\title{
Article \\ Ex Vivo Vibration Spectroscopic Analysis of Colorectal Polyps for the Early Diagnosis of Colorectal Carcinoma
}

\author{
Alla Synytsya ${ }^{1, * \mathbb{D}}$, Aneta Vaňková ${ }^{1}$, Michaela Miškovičová ${ }^{2}$, Jaromír Petrtýl ${ }^{3}$ and Luboš Petruželka ${ }^{2}$ \\ 1 Department of Analytical Chemistry, University of Chemistry and Technology Prague, Technická 5, \\ 16628 Prague, Czech Republic; vankovaa@vscht.cz \\ 2 Department of Oncology, First Faculty of Medicine, Charles University in Prague and General University \\ Hospital in Prague, U Nemocnice 2, 12800 Prague, Czech Republic; michaela.miskovicova@vfn.cz (M.M.) \\ lubos.petruzelka@vfn.cz (L.P.) \\ 3 4th Internal Clinic-Gastroenterology and Hepatology, First Faculty of Medicine, Charles University in \\ Prague and General University Hospital in Prague, U Nemocnice 2, 12800 Prague, Czech Republic; \\ jaromir.petrtyl@vfn.cz \\ * Correspondence: sinical@vscht.cz
}

check for updates

Citation: Synytsya, A.; Vaňková, A.; Miškovičová, M.; Petrtýl, J.; Petruželka, L. Ex Vivo Vibration Spectroscopic Analysis of Colorectal Polyps for the Early Diagnosis of Colorectal Carcinoma. Diagnostics 2021, 11, 2048. https://doi.org/ 10.3390/diagnostics11112048

Academic Editors:

Lucía Inglada-Pérez and José Perea

Received: 3 October 2021

Accepted: 31 October 2021

Published: 4 November 2021

Publisher's Note: MDPI stays neutral with regard to jurisdictional claims in published maps and institutional affiliations.

Copyright: (c) 2021 by the authors. Licensee MDPI, Basel, Switzerland. This article is an open access article distributed under the terms and conditions of the Creative Commons Attribution (CC BY) license (https:/ / creativecommons.org/licenses/by/ $4.0 /)$.

\begin{abstract}
Colorectal cancer is one of the most common and often fatal cancers in humans, but it has the highest chance of a cure if detected at an early precancerous stage. Carcinogenesis in the colon begins as an uncontrolled growth forming polyps. Some of these polyps can finally be converted to colon cancer. Early diagnosis of adenomatous polyps is the main approach for screening and preventing colorectal cancer, and vibration spectroscopy can be used for this purpose. This work is focused on evaluating FTIR and Raman spectroscopy as a tool in the ex vivo analysis of colorectal polyps, which could be important for the early diagnosis of colorectal carcinoma. Multivariate analyses (PCA and LDA) were used to assist the spectroscopic discrimination of normal colon tissue, as well as benign and malignant colon polyps. The spectra demonstrated evident differences in the characteristic bands of the main tissue constituents, i.e., proteins, nucleic acids, lipids, polysaccharides, etc. Suitable models for discriminating the three mentioned diagnostic groups were proposed based on multivariate analyses of the spectroscopic data. LDA classification was especially successful in the case of a combined set of 55 variables from the FTIR, FT Raman and dispersion Raman spectra. This model can be proposed for ex vivo colorectal cancer diagnostics in combination with the colonoscopic extraction of colon polyps for further testing. This pilot study is a precursor for the further evaluation of the diagnostic potential for the simultaneous in vivo application of colonoscopic Raman probes.
\end{abstract}

Keywords: colon polyps; colorectal carcinoma; early cancer diagnosis; vibrational spectroscopy; chemometrics

\section{Introduction}

Colorectal cancer is one of the most common and often fatal cancers in humans globally. However, among all malignant neoplasms of the intestine, it has the highest chance of a cure if it is detected at an early stage as a precancerous lesion [1]. Carcinogenesis in the colon or rectum begins as uncontrolled growth in the inner layers towards the intestinal lumen, forming polyps. Some of these polyps, known as neoplastic or adenomatous, can undergo a gradual transformation, and most of them can finally be converted to colon cancer $[2,3]$. This gradual development of normal intestinal epithelium into carcinoma occurs as a result of several successive genetic mutations, some of which are inherited, while others are acquired [4]. These changes usually occur slowly over many years, so the disease can be prevented by early detection and through the removal of adenomas before they develop into cancer.

Early diagnosis and endoscopic resection of adenomatous polyps is the main approach for the screening and prevention of colorectal cancer. Colonoscopy and histopathology are 
now the standard methods for screening and diagnosing colorectal tissues. Colonoscopy in combination with polypectomy is able to reduce the incidence and mortality of colorectal cancer [5]. Colonoscopy is currently the most accurate and versatile diagnostic test for colorectal carcinoma because it can localize and biopsy lesions throughout the colon, detect neoplasms, and remove adenomatous polyps that could be precursors of cancer. Although colonoscopic screenings have significantly increased the survival rate of patients with colorectal cancer, it remains a challenge to distinguish adenomas and early adenocarcinomas from benign hyperplastic polyps using colonoscopy. This difficulty is mainly because conventional white light reflection colonoscopy relies heavily on the subjective visual assessment of colorectal polyps.

To make a definitive diagnosis of colorectal carcinoma, samples of suspicious tissue biopsies should be subjected to histological examination based on microscopic examination using paraffinization and specific dyes. A waxed tissue block is cut into very thin slices. After further treatments, the slices are placed onto a sample slide and examined under a microscope to determine whether it is a tumor, benign or malignant, and what type it belongs to [6-8]. However, routine histopathological methods applied to analyses of suspected cancerous or precancerous lesions have several disadvantages. Sample preparation procedures with an evaluation of the tissue last approximately 7-10 days, and the entire result often depends on the experience of pathologists and can be highly subjective. Therefore, despite the common diagnostic methods mentioned above, there is still a request for novel, effective, and non-expensive approaches for the early diagnosis of adenomatous polyps for the prevention of colorectal cancer.

Vibration spectroscopy, both infrared and Raman, can be a powerful tool for the early diagnosis of colorectal cancer in several main areas: (i) ex vivo analysis of biopsies of colorectal tissue, including polyps removed by colonoscopy; (ii) endoscopic analysis of the colon cavity in vivo; (iii) analysis of intact intestinal epithelial cells; (iv) visualization and mapping of histological sections of colorectal tissues, and (v) analysis of the biological fluids and derived samples (blood plasma, isolated serum proteins, etc.). It has been shown that both of these methods can support the standard techniques mentioned above and can significantly improve the clinical diagnosis of colon cancer [9-11]. Various methods and techniques of vibrational spectroscopy have proven to be effective in the analysis of colorectal tissues in vivo [12-14], in situ or ex vivo [15-18]. Single living cells of the intestinal epithelium will also be subjected to vibrational spectroscopic evaluation in order to diagnose colorectal cancer [19-21]. Distinguishing between benign and malignant polyps can be achieved via spectroscopic visualization of their histological characteristics, including tissue $[7,22,23]$ and subcellular [24] structures. Moreover, non-invasive analysis of the blood serum [15,25], blood plasma [26,27], or isolated serum proteins [28,29] by chiroptical and vibrational spectroscopy could also help in the early detection of this disease.

To distinguish between normal, benign, and malignant colon tissue samples based on collected spectroscopic data, it is often necessary to employ multivariate statistical methods to extract diagnostic information that is not available in conventional spectral comparisons. Statistical methods used for spectroscopic diagnostics can be divided into controlled and uncontrolled methods [30]. To make a decision, the former approach relies only on vibrational spectra, while the latter relies on additional information obtained by the gold standard method, which is most often from classical histopathology. Principal component analysis (PCA) is often used as an unsupervised approach [30-33]. This technique reduces the number of variables and evaluates the spectroscopic data in the first approximation. A controlled approach is then introduced, such as linear discriminant analysis (LDA), which takes advantage of PCA and the histopathological findings to help classify tissue samples more efficiently $[30,31,34,35]$. For example, infrared spectral histopathology is able to distinguish between different types of tissues and their pathologies in sections of colon cancer tissue [7]. A supervised algorithm based on the random forest methodology was trained using classical histopathology, and was then used to identify tissue types and areas of colon adenocarcinoma. A high correspondence was shown between the images 
obtained by immunohistochemistry and classical and infrared spectral histopathology, with the latter method being able to detect changes in the composition of intestinal tissue without the need for labeling.

The aim of this work is an evaluation of vibrational spectroscopic methods, i.e., Fourier transform (FT) infrared spectroscopy (FTIR) with attenuated total reflection (ATR), FT Raman $\left(\lambda_{\mathrm{ex}}=1064 \mathrm{~nm}\right)$, and dispersion Raman $\left(\lambda_{\mathrm{ex}}=785 \mathrm{~nm}\right)$ spectroscopy as tools in the ex vivo analysis of colorectal polyps for the identification stage development of adenomatous polyps, which might be important for the early diagnosis of colorectal carcinoma. Multivariate analyses, namely PCA and LDA, were used to assist in the discrimination of normal, benign, and malignant colon tissues via vibrational spectroscopy.

\section{Materials and Methods}

\subsection{Human Colorectal Tissue Samples}

Ten patients aged 52 to 85 years undergoing routine colonoscopic examination at the 4th Internal Clinic-Gastroenterology and Hepatology of the 1st Faculty of Medicine and the General University Hospital in Prague (Charles University, Prague, Czech Republic) participated in this study. Colorectal polyps measuring 3-6 $\mathrm{mm}$ were taken with disposable biopsy forceps, and were subjected to a histological examination and spectroscopic analyses. Seven of the participating patients had histologically proven adenomatous colon polyps of low grade G1, and three patients had adenocarcinomatous polyps of intermediate grade G2: (i) polyp of invasive moderately differentiated adenocarcinoma of ascending colon with extensive involvement, (ii) polyp of invasive colon mucosal carcinoma with submucosal involvement, and (iii) polyp with structural features of invasive rectal adenocarcinoma. As samples of normal colon tissue, histologically confirmed samples of the non-tumor area of the colon were used, obtained during elective surgery for the medical treatment of colorectal cancer in fourteen patients of the Department of Oncology of the 1st Faculty of Medicine, Charles University and General University Hospital in Prague. All patients who kindly agreed to participate in this project signed their informed consent, and ethical approval for this study was obtained from the Ethics Committee of the 1st Faculty of Medicine and the General University Hospital in Prague.

\subsection{Spectroscopic Measurements}

Colon tissue samples measuring 3-6 mm were gently washed in $0.9 \% \mathrm{NaCl}$ and were quickly dried on filter paper to remove the excess wash solution. Then, the samples were placed on a sample slide and analyzed via FTIR and Raman spectroscopy at six independent sites at $22^{\circ} \mathrm{C}$.

The FTIR spectra of the colon tissue samples were recorded on a Nicolet iS50 FTIR spectrometer (Thermo Fisher Scientific, Waltham, MA, USA) using the ATR accessory (ZnSe crystal) with a resolution of $4 \mathrm{~cm}^{-1}$ in the range of $4000-400 \mathrm{~cm}^{-1}$. The samples were dried on filter paper, placed on an ATR crystal, and then evenly pressed by a calibrated pressure tower. Five hundred and twelve scans were collected for each spectrum. Smoothing, ATR and baseline corrections were performed using the OMNIC 8.2 software (Thermo Fisher Scientific, Waltham, MA, USA).

The FT Raman spectra of colon tissue samples were recorded on a Bruker FT Raman (FRA 106/S, Equinox 55/S) spectrometer (Bruker, Billerica, MA, USA) equipped with a quartz beam splitter and a Ge detector cooled with liquid $\mathrm{N}_{2}$. A Nd:YAG laser $\left(\lambda_{\mathrm{ex}}=1064 \mathrm{~nm}\right.$, Coherent, Santa Clara, CA, USA) was used for excitation. The power of the laser focused on the sample was $\sim 60 \mathrm{~mW}$. One thousand and twenty four independent scans were co-added to generate each individual Raman spectrum with a resolution of $2 \mathrm{~cm}^{-1}$.

Dispersion Raman spectra (region $400-3100 \mathrm{~cm}^{-1}$, resolution $2 \mathrm{~cm}^{-1}$ ) of the colon tissue samples were recorded on a B\&W Tek i-Raman Plus spectrometer (B\&W Tek Inc., Newark, DE, USA) equipped with a diode laser $\left(\lambda_{\mathrm{ex}}=785 \mathrm{~nm}\right.$, power $90 \mathrm{~mW}$, which corresponds to $20 \%$ of the maximal power $450 \mathrm{~mW}$ ) and a BAC 151A Raman microscope 
with a $100 \times$ objective. These objectives are capable of providing a laser spot diameter of approximately 10-12 $\mu \mathrm{m}$. Each spectrum was generated by the accumulation of 20 scans with a laser exposure time of $20 \mathrm{~s}$ per scan. No spectral or visual changes were observed during the scanning procedure.

The model reference compounds (pork fat, phosphatidylcholine from egg yolk, calf thymus DNA, myoglobin from equine skeletal muscle, human serum albumin (HSA), collagen from rat tail tendon, sodium hyaluronate from rooster comb, chondroitin sulfate A sodium salt from bovine trachea, and glycogen from bovine liver) corresponding to major tissue macromolecules were purchased from Sigma Aldrich (St. Louis, MO, USA). The spectroscopic measurements of these compounds were made under the same conditions as the measurements of the colon tissue samples.

\subsection{Statistical Analyses of Spectroscopic Data}

Vibrational spectra of the colon tissue samples recorded at independent sites were exported to Origin 6.0 (Microcal Origin, Northampton, MA, USA) software as the ASCII data files for further processing (smoothing, baseline correction, etc.). The spectra were normalized according to the appropriate tissue marker bands, i.e., amide vibrations in proteins $\sim 1650 \mathrm{~cm}^{-1}$ and $\sim 3290 \mathrm{~cm}^{-1}$ for FTIR and CH stretching vibrations at $\sim 2930 \mathrm{~cm}^{-1}$ for FT Raman and dispersion Raman. Then the normalized spectra were imported to Unscrambler X 10.5.1 (CAMO Software AS, Oslo, Norway) software for a statistical evaluation, using PCA to reduce the highly correlated multidimensional spectroscopic datasets to a smaller number of uncorrelated principal components (PCs). The results of the PCA were represented by loading and component score plots. Comparing the PCA loading curves of the three chosen PCs, three sets of 15-20 variables in each for FTIR (20), FT Raman (15), and dispersion Raman (20) data were selected, normalized, and applied for LDA classification using XLSTAT (Addinsoft, Paris, France) software. The quality of these models was evaluated by the leave-one-out cross-validation procedure. The LDA results were represented by the squared Mahalanobis distances, variables/factor correlation, and factor score plots. The distances between the three diagnostic groups (normal colon tissues, benign and malignant colon polyps) were calculated from the squared Mahalanobis distances according to Equation (A1) (see Appendix A).

\section{Results}

\subsection{Vibrational Spectra of Normal Colon Tissues, and Adenomatous and Adenocarcinomatous Polyps}

Average (mean $\pm \mathrm{SD}$ ) vibrational spectra of control colon tissues $(n=10)$, adenomatous $(n=7)$ and adenocarcinomatous $(n=3)$ colon polyps and the corresponding difference spectra (adenoma minus normal, carcinoma minus normal and carcinoma minus adenoma) are represented in Figure 1 left and right panels, respectively; the FTIR $\left(900-3750 \mathrm{~cm}^{-1}\right)$, FT Raman (500-3100 $\left.\mathrm{cm}^{-1}\right)$ and dispersion Raman $\left(400-3100 \mathrm{~cm}^{-1}\right)$ spectra are grouped in the top, middle and bottom panels, respectively. The band assignments are summarized in Table S1 in accordance with literature $[17,36-50]$ and the corresponding vibration spectra of the model reference compounds (Figure S1a-c).

The analysis of the vibrational spectra is sometimes complicated, since the absorption bands often overlap with one another. Second derivative spectroscopy is a technique that helps detect overlapping bands. Therefore, the positions of the shoulders in the spectra were determined using the second derivative algorithm. 


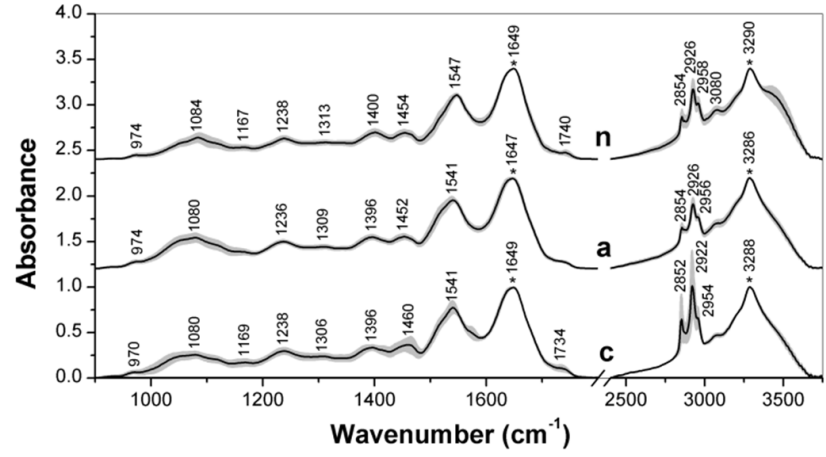

(a)

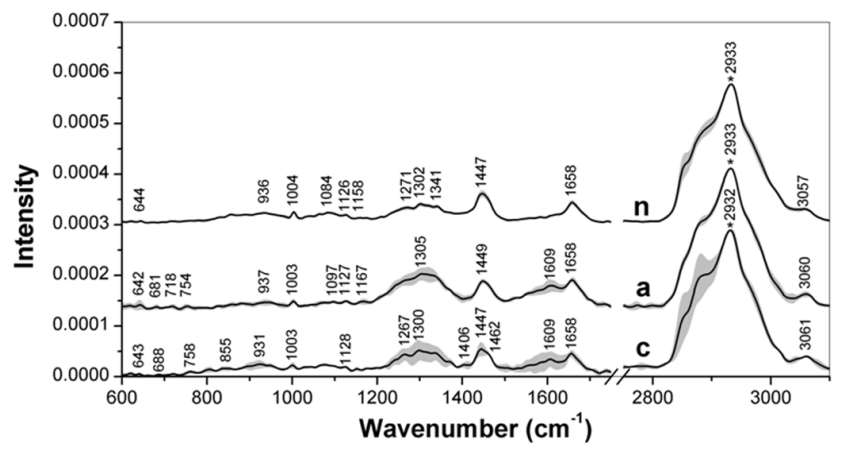

(c)

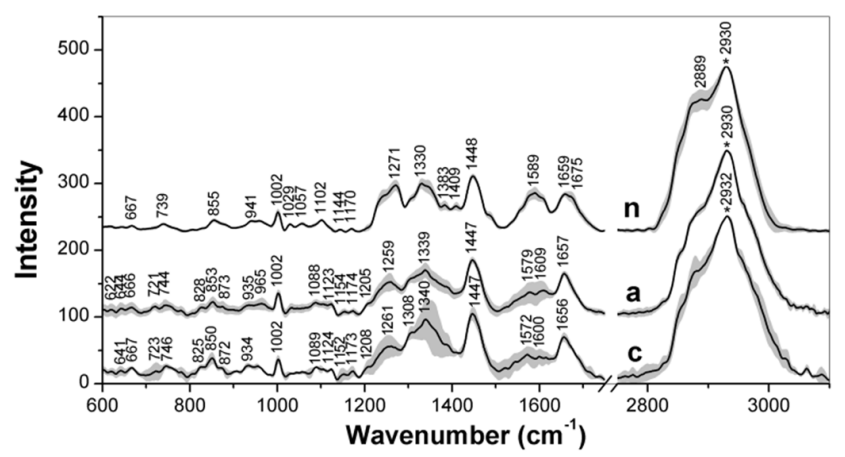

(e)

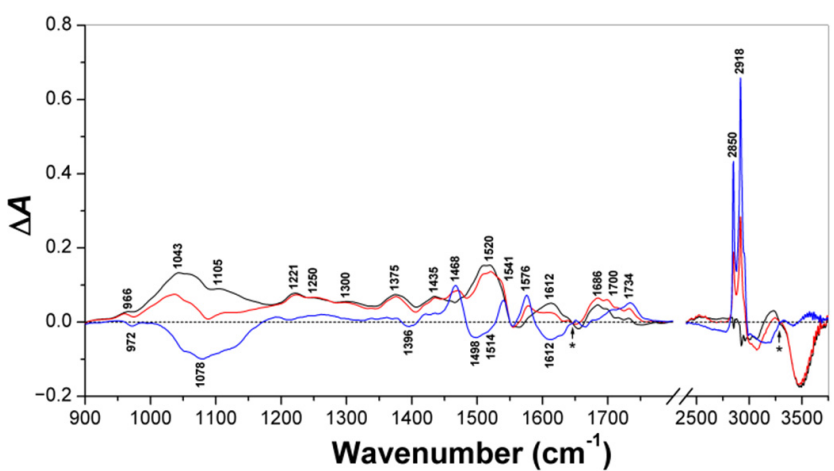

(b)

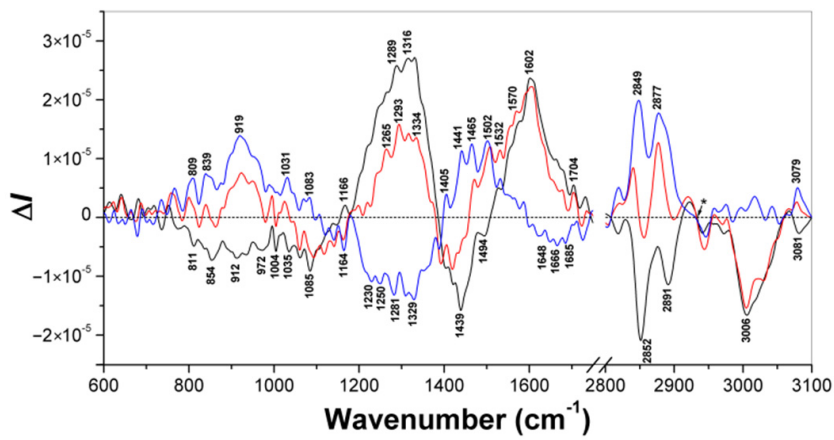

(d)

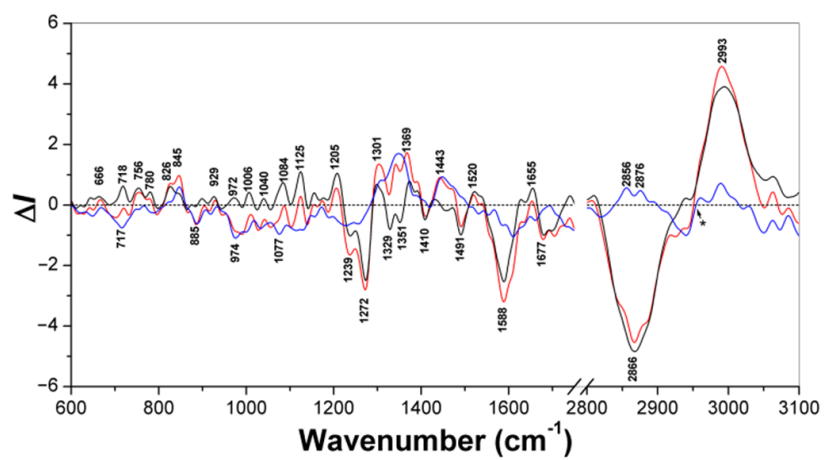

(f)

Figure 1. (Left panels) The average (black solid lines) and standard deviation (SD; gray space) FTIR (a), FT Raman (c) and dispersion Raman (e) spectra of the normal colon tissues " $n$ ", and adenomatous " $a$ " and adenocarcinomatous " $c$ " colon polyps. (Right panels) The FTIR (b), FT Raman (d), and dispersion Raman (f) difference spectra adenoma minus normal ("a-n", black), carcinoma minus normal ("c-n", red) and carcinoma minus adenoma ("c-a", blue); the average spectra were normalized at wavenumbers with an asterisk.

\subsubsection{FTIR Spectra $\left(900-3750 \mathrm{~cm}^{-1}\right)$}

As shown in Figure 1a, the characteristic bands of the proteins at $3286-3290 \mathrm{~cm}^{-1}$ (amide A), 1647-1649 $\mathrm{cm}^{-1}$ (amide I) and 1541-1547 $\mathrm{cm}^{-1}$ (amide II) were predominate in the FTIR spectra of all of the samples [36,38,39]. The amide II band of adenomatous and adenocarcinomatous polyps was shifted by $6 \mathrm{~cm}^{-1}$ to lower wavenumbers compared with the control colon tissue. A more detailed analysis of the spectral region of this band was made using the second derivatives, which showed two minima at 1547 and $1541 \mathrm{~cm}^{-1}$ (Figure S2). In the raw normal colon tissues-adenomatous polyps-adenocarcinomatous polyps, the first component decreased while the second component grew. Similar changes were observed in the region of the smaller negative band at $1576 \mathrm{~cm}^{-1}(C=C$ stretching vibration in aromatic amino acids or nucleic bases), which corresponded to the shoulder in the adenocarcinoma spectrum. The perturbations in the region of amide II could be 
associated with a change in the composition of proteins, as the position of this band varied greatly in different proteins (Figure S1a). The FTIR spectra also contained several bands at 2954-2958, 2922-2926, 2852-2854, and 1452-1460 $\mathrm{cm}^{-1}$ assigned to stretching and bending vibrations of $\mathrm{CH}_{3}$ and $\mathrm{CH}_{2}$ groups in the fats and aliphatic amino acids $[17,40]$.

The characteristic bands of the $\mathrm{CH}_{2}$ groups at 2922, 2852, and $1460 \mathrm{~cm}^{-1}$ were found to be more pronounced for adenocarcinomatous polyps due to the contribution of fats. The band or shoulder near $1740 \mathrm{~cm}^{-1}$ was assigned to the $\mathrm{C}=\mathrm{O}$ stretching vibration in the fats. IR bands at $1396-1400 \mathrm{~cm}^{-1}$ were assigned to symmetric stretching of $\mathrm{COO}^{-}$groups in the Asp and Glu residues of the proteins [40]. The band at $1236-1238 \mathrm{~cm}^{-1}$ originated from amide III vibrations in the proteins, $=\mathrm{CH}$ bending vibration in the unsaturated fatty acids, and antisymmetric stretching vibrations of $\mathrm{PO}_{2}{ }^{-}$in the phospholipids $[39,41]$. The region of 930-1170 $\mathrm{cm}^{-1}$ had several overlapping bands assigned, mainly to $\mathrm{CO}$ and CC stretching vibrations in carbohydrates (glycogen and glycosaminoglycans) and lipids; the band at $1080-1084 \mathrm{~cm}^{-1}$ also contributed to symmetric stretching vibrations of $\mathrm{PO}_{2}^{-}$in the phospholipids and nucleic acids $[36,41]$.

The FTIR difference spectra between both types of polyps and normal colon tissue, assigned as " $\mathrm{a}-\mathrm{n}$ " and " $\mathrm{c}-\mathrm{n}$ ", respectively, and between cancerous and adenomatous polyps, "c-a", are represented in Figure 1b. The first two curves demonstrated positive bands at 1686, 1520,1435, 1375, 1300, 1250, 1221, 1043, and $966 \mathrm{~cm}^{-1}$ that are characteristic of colon polyps of both types. These bands originated mainly from proteins, nucleic acids, and polysaccharides [37]. The positive bands at $1612 \mathrm{~cm}^{-1}\left(\mathrm{COO}^{-}\right.$stretching) and $1105 \mathrm{~cm}^{-1}$ (CO and CC stretching) were more pronounced for adenomatous polyps; both of these bands may contribute to glycosaminoglycans. In contrast, the positive bands at $2918,2850,1734$, and $1468 \mathrm{~cm}^{-1}$ indicated the prevalence of lipids in cancerous polyps. The last curve, "c-a", showed several positive bands at 2918, 2850, 1736, and $1468 \mathrm{~cm}^{-1}\left(\mathrm{CH}_{2}\right.$ and $\mathrm{C}=\mathrm{O}$ groups in lipids) and negative bands at 1612, 1498, 1396, and $1078 \mathrm{~cm}^{-1}$ (phenyl, carboxylate, and phosphate groups). The negative band at $1498 \mathrm{~cm}^{-1}$ with a shoulder near $1514 \mathrm{~cm}^{-1}$ could be assigned to in-plane $\mathrm{C}=\mathrm{C}-\mathrm{H}$ bending and $\mathrm{C}=\mathrm{C}$ stretching vibrations of the phenyl ring in the aromatic amino acids Phe and Tyr, respectively [40,42-44].

\subsubsection{FT Raman Spectra $\left(500-3100 \mathrm{~cm}^{-1}\right)$}

The most intense band in the FT Raman spectra of both normal colon tissues and the colorectal polyps was found at $\sim 2933 \mathrm{~cm}^{-1}$ (Figure 1c). This band corresponded mainly to the symmetric stretching vibration of the methyl groups in the aliphatic residues; the corresponding band of bending vibration was found at $1448 \mathrm{~cm}^{-1}$. The shoulders at 2882 , 2850, and 1460-1463 $\mathrm{cm}^{-1}$, assigned to the vibrations of the $\mathrm{CH}_{2}$ groups, were pronounced for the adenocarcinomatous polyps, which indicate an increased amount of lipids [45]. The bands at 3057-3061, and $1658 \mathrm{~cm}^{-1}$ originated mainly from amide vibrations in the proteins. Several bands of unsaturated compounds at 3008-3015, 1500-1590, and $1267 \mathrm{~cm}^{-1}$ were more pronounced for colorectal polyps than for normal colon tissue. Two bands of the polyps at 1609 and $1406 \mathrm{~cm}^{-1}$ arose from stretching vibrations of the $\mathrm{COO}^{-}$groups. For all of the samples, the narrow band near $1004 \mathrm{~cm}^{-1}$ corresponded to the ring vibration of Phe in proteins. The bands in the region of $1120-1174 \mathrm{~cm}^{-1}$ mainly originated from CO and CC stretching vibrations of polysaccharides, and the bands in the region of $1077-1097 \mathrm{~cm}^{-1}$ originated from phosphate vibrations in the phospholipids and nucleic acids.

The FT Raman difference spectra between the diagnostic groups of colon tissues are shown in Figure 1d. The " $\mathrm{a}-\mathrm{n}$ " and " $\mathrm{c}-\mathrm{n}$ " curves demonstrated two positive regions of $1532-1685 \mathrm{~cm}^{-1}$ and $1250-1334 \mathrm{~cm}^{-1}$, which had contribution mainly from the vibrations of the peptide groups and aromatic amino acid side chains in the proteins. These areas may indicate an increased protein content in adenomatous polyps compared with the control; however, for adenocarcinomas, it is difficult to assess these differences due to the small number of samples and the high heterogeneity of this group. These areas may indicate an increased protein content in adenomatous polyps compared with the control; however, for adenocarcinomas, it is difficult to assess these differences due to the small 
number of samples and the high heterogeneity of this group. In all of these curves, the bands of $\mathrm{CH}_{2}$ vibrations found at 2877-2891, 2840-2852, and 1465-1470 $\mathrm{cm}^{-1}$ indicated that the lipid contribution was maximal for cancerous polyps and minimal for adenomatous polyps [46], while normal colon tissues demonstrated an intermediate contribution. Curve "c-a" showed several negative bands at 1648-1685 and 1230-1329 $\mathrm{cm}^{-1}$ associated mainly with the amide I and amide III vibrations of the proteins, respectively. The next positive region of $809-1083 \mathrm{~cm}^{-1}$ with the main maximum at $919 \mathrm{~cm}^{-1}$ contributes to the vibrations of lipids, polysaccharides and the phosphate groups [46]. These negative and positive parts of the curve correspond to the assumption about the possible predominance of proteins in adenomatous polyps and lipids and polysaccharides in adenocarcinomatous polyps. However, it is difficult to assert this with certainty because of the large standard deviation of the adenocarcinoma spectra.

\subsubsection{Dispersion Raman Spectra (450-3100 $\mathrm{cm}^{-1}$ )}

In the region of $\mathrm{CH}$ stretching vibrations $\left(2800-3100 \mathrm{~cm}^{-1}\right)$, the average dispersion Raman spectra of the normal colon tissue and two types of colorectal polyps (Figure 1e) have the most intense band assigned to the symmetric stretching of methyl groups at 2930-2932 $\mathrm{cm}^{-1}$ [45]. Several bands at 2889, 1675, 1589, 1409, 1330, 1271, 1144, 1057, and $941 \mathrm{~cm}^{-1}$ were pronounced in the spectrum of the normal colon tissue. In contrast, bands near 1340, 1308, 1208, 1174, 1153, 1123, 1088, 934, 873, 825, and $722 \mathrm{~cm}^{-1}$ were found in the spectra of the colon polyps. These spectral differences can be explained by expressive changes in the composition and structure of the biochemical tissue components, mainly proteins and lipids, and, to a lesser extent, polysaccharides and nucleic acids. The bands at $1656-1659$ and $1259-1271 \mathrm{~cm}^{-1}$ arose from various vibrations of proteins and unsaturated lipids, and the bands at $\sim 1448$ and $1330-1340 \mathrm{~cm}^{-1}$ were assigned mainly to $\mathrm{CH}_{2}, \mathrm{CH}_{3}$, and $\mathrm{CCH}$ bending vibrations of aliphatic amino acids and lipids [45]. Bands at $1579-1589,1205-1228,1028-1033,1002,850-855,825-828$, and $739-746 \mathrm{~cm}^{-1}$ contribute from aromatic amino acids in proteins. Bands in the region of $1174-1102 \mathrm{~cm}^{-1}$ originated mainly from COC, CO, and CC vibrations in polysaccharides and lipids, and the band at $1083-1089 \mathrm{~cm}^{-1}$ arose from symmetric stretching vibrations of $\mathrm{PO}_{2}{ }^{-}$groups in the phospholipids and nucleic acids.

The difference dispersion Raman spectra of " $\mathrm{a}-\mathrm{n}$ " and " $\mathrm{c}-\mathrm{n}$ " demonstrated positive difference bands at 2993-2995, 1655, 1520, 1369-1373, 1298-1301, 1205, 1125, 929, 845, $826,780,756,718$, and $666 \mathrm{~cm}^{-1}$ that are characteristic of colon polyps (Figure 1f). These bands contribute proteins, lipids, and unsaturated compounds (see Table S1). The band at $1084-1087 \mathrm{~cm}^{-1}$ was assigned to the vibration of phosphate groups, and the positive difference band near $845 \mathrm{~cm}^{-1}$ contributed to the $\mathrm{C} 1 \alpha \mathrm{H}$ bending vibration in glycogen. In contrast, the negative difference bands at 2866, 1677, 1588, 1491, 1410, 1351, 1329, 1272 , and $1239 \mathrm{~cm}^{-1}$ were characteristic of normal colon tissues. The positive band at 2993-2995 $\mathrm{cm}^{-1}$ and the negative band at $2866 \mathrm{~cm}^{-1}$ (C-H stretching region) demonstrated the difference between normal colon tissues and polyps in the contributions of various alkyl moieties. The difference spectrum " $\mathrm{c}-\mathrm{a}$ " had positive features at 2876, 2856, 1443, and $\sim 1300 \mathrm{~cm}^{-1}$ originating from various vibrations of $\mathrm{CH}_{2}$ groups prevailing in lipids. The negative regions of 1590-1661, 974-1256, and 885-933 $\mathrm{cm}^{-1}$ mainly arose from protein vibrations. Two negative bands at 1077 and $717 \mathrm{~cm}^{-1}$ also contributed to the vibrations of phospholipids and nucleic acids, and the positive band at $847 \mathrm{~cm}^{-1}$ contributed to the $\mathrm{C} 1 \alpha \mathrm{H}$ bending of glycogen.

\subsection{Discrimination of Normal Colon Tissues, and Adenomatous and Adenocarcinomatous Polyps}

A principal component analysis (PCA) was conducted on the FTIR, FT Raman, and dispersion Raman spectra of the normal colon tissues $(n=10)$ and colon polyps $(n=10)$, the latter of which included adenomatous $(n=7)$ and adenocarcinomatous $(n=3)$ polyps measured at six independent locations for each sample. In each case, the combinations of two spectral regions of low and high wavenumbers were chosen for effective discrim- 
ination. For each vibrational spectroscopic method, the first six main components (PCs) were examined. Three of the six that showed significant differences between the three groups of tissue samples were chosen as the main discriminants. Although PC1 covers the largest variation in the dataset, specifically 53\% for FTIR, $63 \%$ for FT Raman, and $42 \%$ for dispersion Raman, it sometimes does not show effective separation of the mentioned groups because of the strong differences among the individual cancerous polyps. So, for example, in the case of FTIR spectra, PC1 separated the first case of adenocarcinoma not only from the rest of the malignant polyps, but also from all other samples, and only PC2 separated the adenomatous polyps from the normal colon tissue, and the adenocarcinoma cases were located between two mentioned groups (Figure S3). Such discrimination could be explained by the higher content of lipids in adenocarcinomas, especially in the first case with greater invasiveness and a wide area of lesions, which was reflected in the spectra. Conversely, the adenoma samples showed less intense lipid bands than the normal tissue. The use of higher PCs made it possible to take into account the contribution of other biochemical components of colon tissues. To improve discrimination, higher PCs were used instead for the FTIR and dispersion Raman spectra. The loading plots of these sets of PCs are shown in Figure 2a,c,e. Three-dimensional component score plots (Figure 2b,d,f) were constructed involving the appropriate combination of PCs, i.e., PC2 $(27 \%)$ vs. PC3 $(13 \%)$ vs. PC4 (3\%) for FTIR, PC1 (63\%) vs. PC2 (20\%) vs. PC3 (5\%) for FT Raman, and PC2 vs. PC3 vs. PC6 for the dispersion Raman. These combinations proved to be the most suitable for distinguishing between normal colon tissue and both types of colon polyps.

\subsubsection{PCA/FTIR (900-1750 $\mathrm{cm}^{-1}$ and $2830-3100 \mathrm{~cm}^{-1}$ )}

According to the 3D score plot for FTIR, the adenomatous polyps had a negative PC2 score, while all of the other samples had a positive PC2 score, with the cancerous polyps located between the clusters of normal colon tissue and adenomatous polyps (Figure 2b).

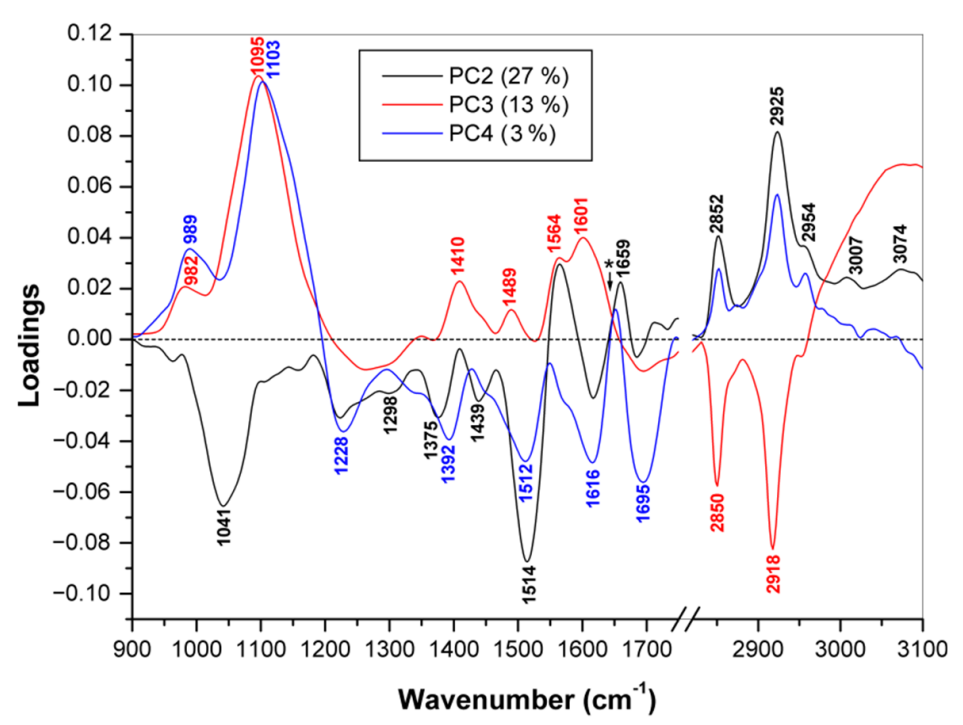

(a)

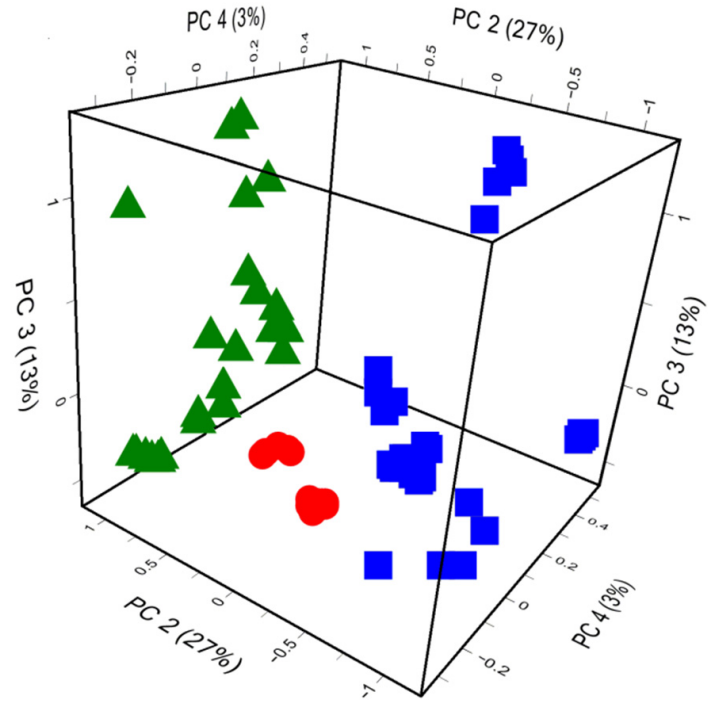

(b)

Figure 2. Cont. 


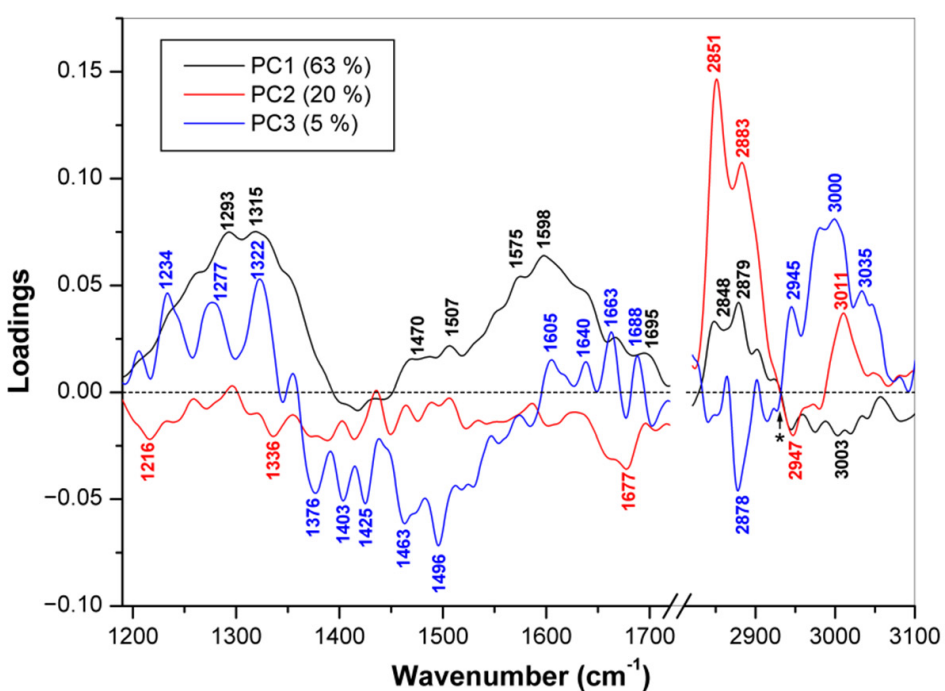

(c)

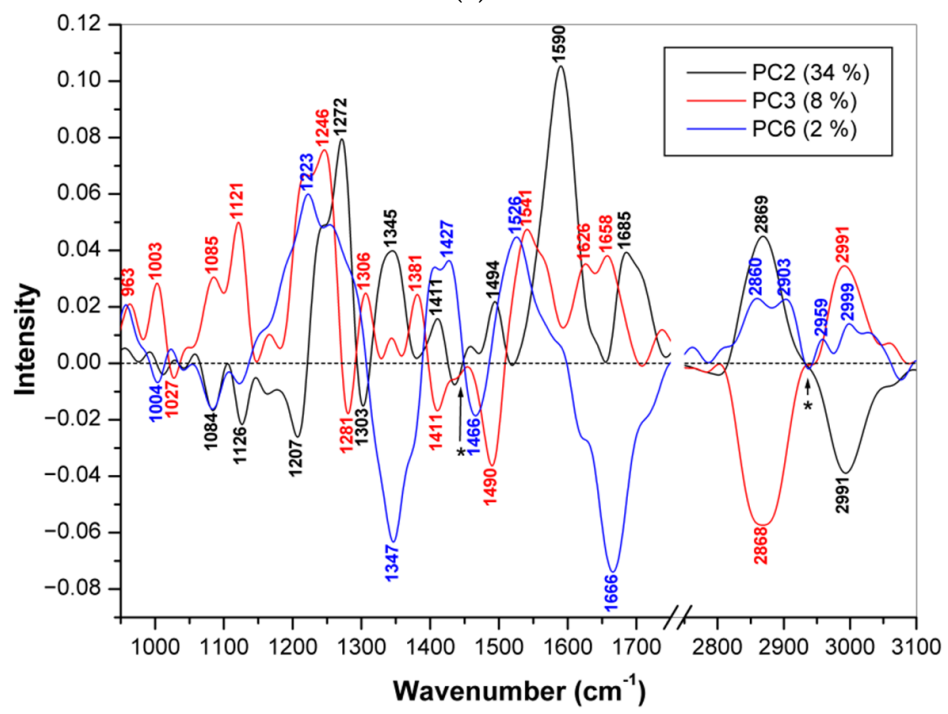

(e)

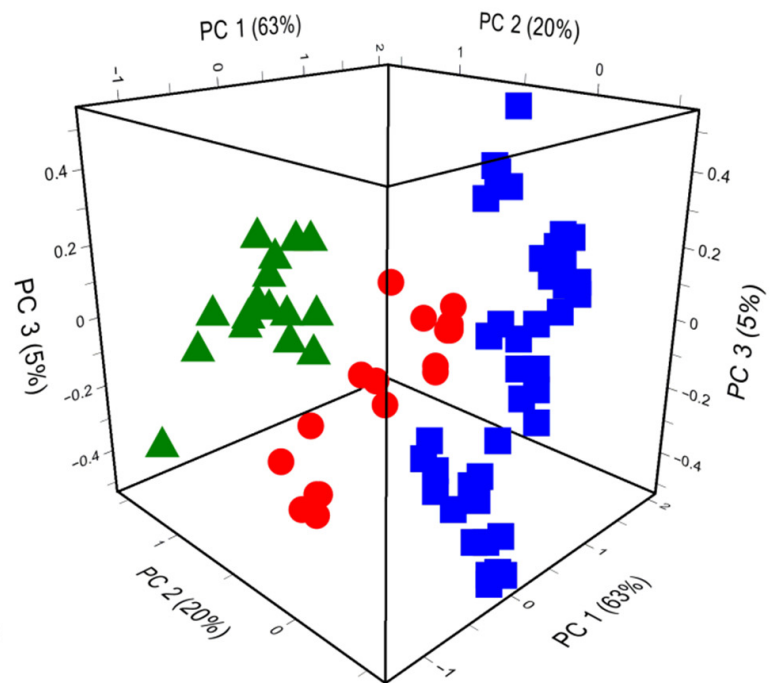

(d)

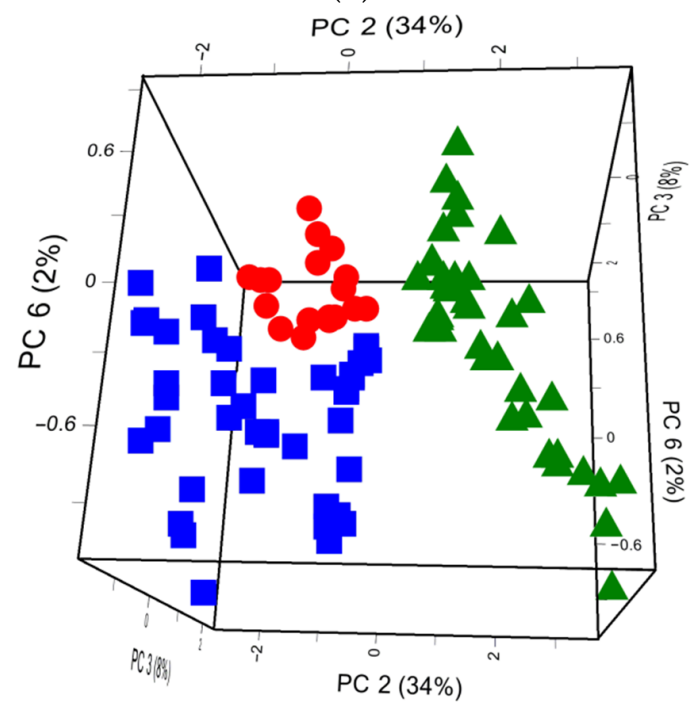

(f)

Figure 2. The loadings plots (left panels) and 3D component score plots (right panels) for three PCs of FTIR (a,b), FT Raman (c,d), and dispersion Raman (e,f) spectra of normal colon tissues (green triangles), adenomatous (blue squares), and adenocarcinomatous (red rings) colon polyps.

The PC3 score, in turn, further separated the adenocarcinomatous polyps from the normal colon tissue cluster; the former had PC 3 values lower than -0.35 , and the latter had values higher than -0.35 . Finally, the PC4 score focused the cancerous polyps around zero and thus also separated them from other samples with negative or positive values. The combination of these three PCs makes it possible to distinguish between all three groups of samples. The loading curve of PC2 has two positive bands at 2925 and $2852 \mathrm{~cm}^{-1}$, indicating the contribution of lipids in normal colon tissue and cancerous polyps, while the negative bands at 1514 and $1041 \mathrm{~cm}^{-1}$ assigned to $C=C$ stretching and $=C H$ bending vibrations in aromatic amino acids, respectively, could indicate higher amounts of proteins in adenomatous polyps (Figure 2a). The latter band also contributes to $\mathrm{CO}$ and $\mathrm{CC}$ vibrations in carbohydrates. The two lipid bands corresponding to those described above for PC2 were negative for $\mathrm{PC} 3$ and positive for PC4, which means that for these two components, the lipids remained key compounds for further discrimination. In addition, the strong positive PC 3 and PC4 bands at $1095-1103 \mathrm{~cm}^{-1}$ indicated the contribution of phosphate groups in the phospholipids and nucleic acids, and two positive PC 3 bands at 1601 and 
$1410 \mathrm{~cm}^{-1}$, as well as the corresponding negative PC 4 bands at 1616 and $1392 \mathrm{~cm}^{-1}$, arose from carboxylate groups in the proteins (Asp and Glu). Therefore, IR bands of all of the mentioned compounds may contribute to PCA discrimination of colon tissues and colon polyps. However, the numerous bands of these biomolecules overlap significantly, making it difficult to determine which component is responsible for the spectroscopic difference at specific wavenumbers.

\subsubsection{PCA/FT Raman $\left(1190-1750 \mathrm{~cm}^{-1}\right.$ and $2820-3100 \mathrm{~cm}^{-1}$ )}

In the case of FT-Raman, none of the PCs used were able to completely separate the malignant polyps from the other two clusters, although PC1 clearly distinguished the normal colon tissues from the adenomatous polyps, the latter having higher PC1 values than the former. The border between these two clusters corresponded to a PC1 value of -0.5 . In addition, the adenomatous polyps were separated by PC1 from the cancerous polyps that were on either side of the former. Additionally, the combination of the two subsequent components of PC2 and PC3 made it possible to completely separate the adenocarcinomatous polyps from the normal colon tissues. As a result, the use of all three mentioned PCs led to a complete separation of clusters of normal tissue and both types of polyps (Figure 2d). The loading curve of PC1 had three regions of positive bands at 1200-1400, 1450-1700, and 2830-2930 $\mathrm{cm}^{-1}$ and one less pronounced negative region at 2930-3100 $\mathrm{cm}^{-1}$ (Figure 2c). The PC2 curve had intense positive bands of lipids at 3011, 2851 , and $2883 \mathrm{~cm}^{-1}$ corresponding to weaker positive PC1 bands at 2848 and $2879 \mathrm{~cm}^{-1}$, so positive values of PC2 indicated samples with high amounts of lipids. In contrast, negative PC2 bands at 1677, 1336, and $1216 \mathrm{~cm}^{-1}$ were associated with protein vibrations. Finally, the positive regions of PC3 at $2945-3035 \mathrm{~cm}^{-1}$ (=CH stretching), $1605-1688 \mathrm{~cm}^{-1}$ (amide I and C $=\mathrm{C}$ stretching), and 1234-1322 $\mathrm{cm}^{-1}$ (amide III and $=\mathrm{CH}$ bending) arose mainly from unsaturated compounds and proteins, while the negative PC3 bands at 2870, $2840,1463,1376$, and $1299 \mathrm{~cm}^{-1}$ were assigned to the vibrations of the $\mathrm{CH}_{2}$ and $\mathrm{CH}_{3}$ groups. As a result, the discrimination was based on differences in the relative contributions of the proteins and lipids, and the ratio between the saturated and unsaturated groups in these biomolecules was also significant.

\subsubsection{PCA/Dispersion Raman (950-1750 $\mathrm{cm}^{-1}$ and $2750-3100 \mathrm{~cm}^{-1}$ )}

In the case of the dispersion Raman spectra, PC2 was able to discriminate the normal colon tissues from colon polyps. Indeed, as seen from the 3D component score graph (Figure 2f), the normal colon tissue cluster was located in the positive PC2 region, while all colon polyps were in the negative region. In addition, the use of a combination of PC3 and PC6 was effective for distinguishing between adenomatous and malignant polyps. Two intense positive bands of the PC2 loading curve at 1590 and $1272 \mathrm{~cm}^{-1}$ were assigned to the $\mathrm{C}=\mathrm{C}$ stretching and $=\mathrm{CH}$ bending vibrations of the aromatic compounds, respectively (Figure 2e). These bands probably originated from the hem moiety of blood hemoglobin $[47,48]$ or rather tissue hemoproteins, including myoglobin and cytochromes $[49,50]$. These bands were enhanced due to the pre-resonance effect, and their positions were displaced due to the denaturation of hemoproteins and changes in the hem environment. The bands at 2991 and $2868 \mathrm{~cm}^{-1}$, which were attributed to various C-H stretching vibrations, had opposite signs on the PC2 and PC3 loading curves. Positive bands of PC 3 at 1246 and $1085 \mathrm{~cm}^{-1}$, in turn, indicated the contribution of phosphate groups. Finally, three negative bands of PC6 at 1666, 1347, and $1004 \mathrm{~cm}^{-1}$ mainly arose from proteins, partially collagen. Consequently, the biochemical background of this discrimination was rather complex and included the contribution of various biomolecules.

\subsubsection{LDA Classification of Colon Tissues/Polyps Using Vibrational Spectroscopic Data}

From the above results, it is evident that the PCA discrimination of normal colon tissue and polyps based on FTIR, FT Raman, or dispersion Raman spectra is not satisfactory for the diagnosis of colorectal carcinoma. Indeed, in the component score plots 
the clusters of normal colon tissues and adenomatous and adenomatous polyps are very close to one another, and therefore it should be difficult to assign a borderline sample to a specific cluster.

To improve discrimination, 15-20 wavenumber values per vibrational spectroscopic method were chosen for the LDA classification (Table 1). The selection of these three sets of variables was made based on a comparison of the difference spectra (Figure $1 \mathrm{~b}, \mathrm{~d}, \mathrm{f}$ ) and the extremes of individual PCs (Figure 2a,c,e). The chosen variables corresponded to specific tissue components, mainly lipids and proteins, but polysaccharides, nucleic acids, and other metabolites may contribute to some of them (see Table S1 for the interpretation). The results of the LDA discrimination of the samples using individual sets or their combination are represented in the factor score plots, variables/factor correlation plots, and the 3D plots of the squared Mahalanobis distances (Figures 3-5). In all of the cases, the samples were successfully separated into three clusters of normal colon tissue, adenomatous and adenocarcinomatous polyps.

Table 1. Variables $\left(\mathrm{cm}^{-1}\right)$ of the FTIR, FT Raman and dispersion Raman spectra used for the discrimination of normal colon tissues, and benign and malignant colon polyps.

\begin{tabular}{|c|c|}
\hline Method & Variables: Wavenumber $\left(\mathrm{cm}^{-1}\right)$ \\
\hline FTIR & $\begin{array}{c}972,989,1043,1078,1103,1221,1300,1375,1392,1410,1435,1468,1512 \\
1576,1612,1695,1734,2850,2917,2954\end{array}$ \\
\hline FT Raman & $\begin{array}{l}1234,1277,1293,1316,1334,1441,1465,1502,1570,1602,1640,1666, \\
2851,3006\end{array}$ \\
\hline Dispersion Raman & $\begin{array}{c}973,1004,1084,1125,1207,1240,1272,1303,1346,1381,1410,1490,1526, \\
1588,1626,1655,1666,1685,2869,2991\end{array}$ \\
\hline
\end{tabular}

The FTIR method demonstrated discrimination between the clusters of normal colon tissue and colon polyps of both types according to F1, and values of F2 additionally separated the clusters of adenomatous polyps from the cluster of cancerous polyps (Figure 3a). A similar but not as effective discrimination was obtained by the dispersion Raman, where one point of malignant polyps was located in proximity to the cluster of benign polyps (Figure 3c). In contrast, in the case of FT Raman, all three clusters were separated by F1, and F2 additionally separated the cluster of adenocarcinomatous polyps from the other two (Figure 3b). However, in this case, the clusters were rather diffuse and situated close to one another, especially those of the two types of colon polyps. The combination of any two methods led to a significant improvement of discrimination in comparison with the individual methods (Figure 3d-f). It is also evident that LDA for the combined model, including all three methods (55 variables), represented the best discrimination. All three clusters were very compact and located in different quadrants, and were well separated from one another, and the points of each cluster were densely packed into narrow areas (Figure 3g).

The correlation between the chosen variables corresponding to specific wavenumbers is represented in variable/factor correlation plots (Figure 4). The FTIR variables were separated by F2 into two groups, one positive and one negative (Figure 4a). The former group (seven variables) mainly corresponded to vibrations of lipids $(2917,2850$, 1734 , and $1468 \mathrm{~cm}^{-1}$ ) and could be nucleic acids or unfolded proteins (2954, 1695, and $\left.1576 \mathrm{~cm}^{-1}\right)$; these bands could be markers of a malignancy for colon polyps. The latter group (13 variables) mainly corresponded to specific vibrations of proteins (including collagens), nucleic acids, and polysaccharides pronounced for adenomatous polyps. Most FT Raman variables were associated with proteins and were located in the region of positive F1, while only three variables of lipid vibrations $\left(3006,2877\right.$, and $2851 \mathrm{~cm}^{-1}$ ) were found in the negative region of F1 (Figure $4 \mathrm{~b}$ ). In contrast, the dispersion Raman variables (Figure 4c) were arranged more or less diffusely, but it was possible to distinguish the clusters corresponding to the vibrations of proteins $\left(1666,1655,1626,1004\right.$, and $\left.973 \mathrm{~cm}^{-1}\right)$, unsaturated compounds $\left(2869,1685,1490,1272\right.$, and $\left.1240 \mathrm{~cm}^{-1}\right)$, and polysaccharides 
(1125 and $1084 \mathrm{~cm}^{-1}$ ). In the case of the combined sets of variables (Figure $4 \mathrm{~d}-\mathrm{g}$ ), the variables/factor plot demonstrates the correlation between variables from different methods. For example, in the case of a combined FTIR + FT Raman dataset, the variables corresponding to the stretching vibrations of $\mathrm{CH}$ in aliphatic groups at $2954-2850 \mathrm{~cm}^{-1}$ are located in quadrant I (Figure 4d). In the case of triple combination, the main group associated with proteins and polysaccharides was located in the region of positive F1, while the lipid bands were found in quadrant III (negative F1 and F2) and six vibrations associated with unsaturated compounds in quadrant IV (Figure 4g). These three regions coincided with clusters of adenomatous polyps, adenocarcinomatous polyps, and normal colon tissue.

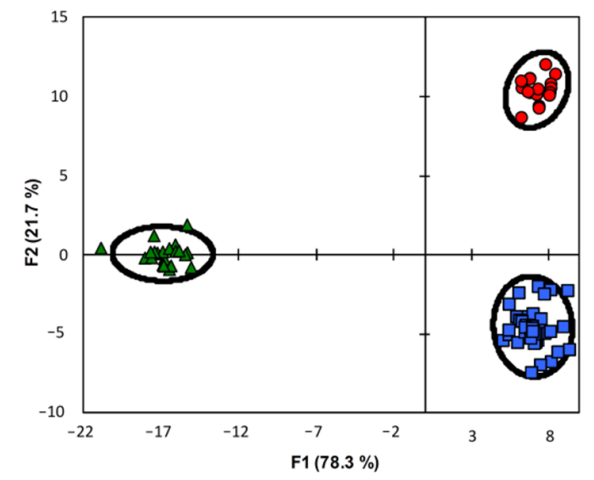

(a)

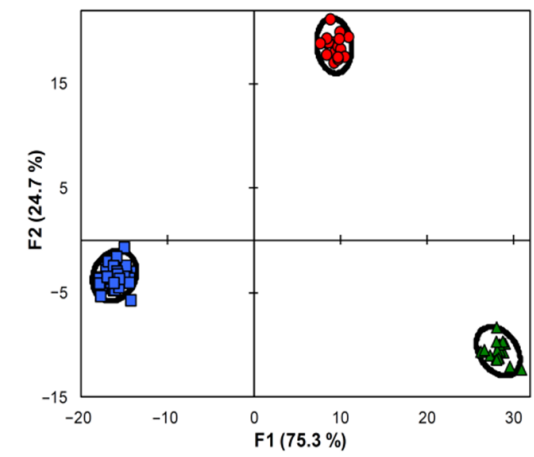

(d)

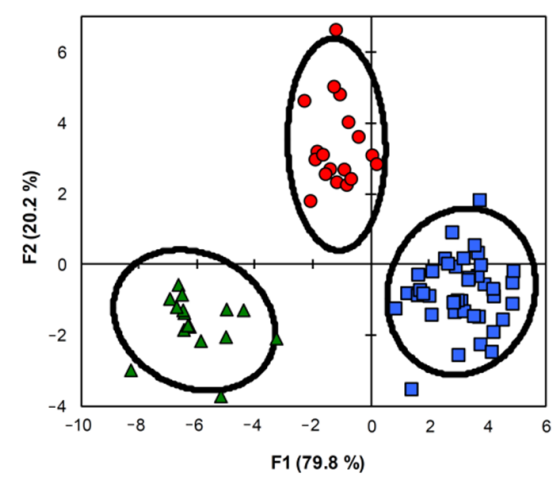

(b)

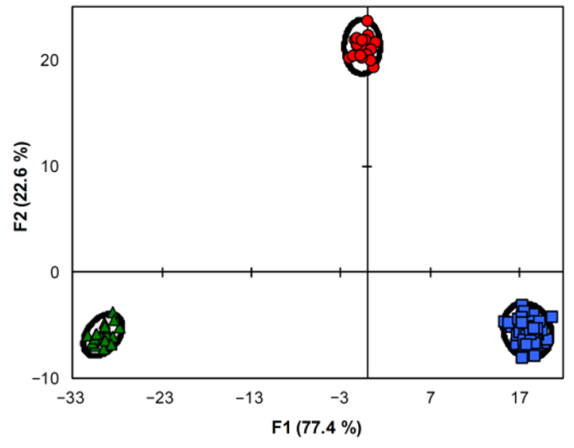

(e)

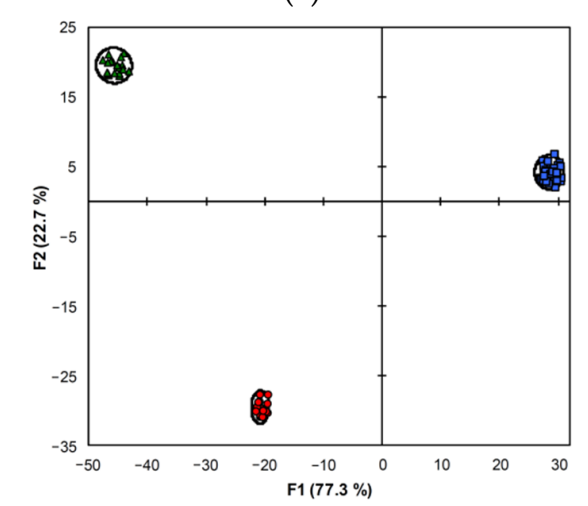

(g)

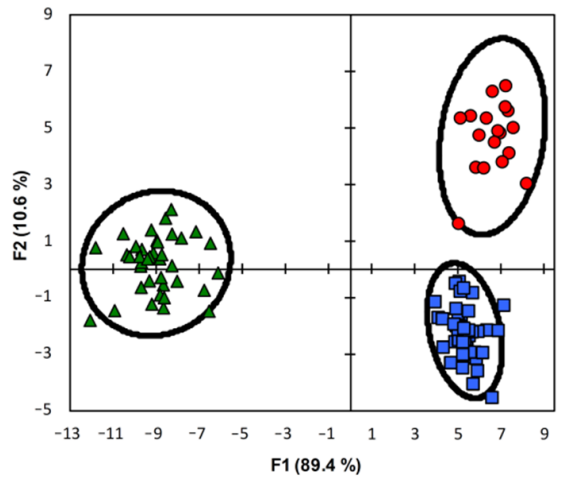

(c)

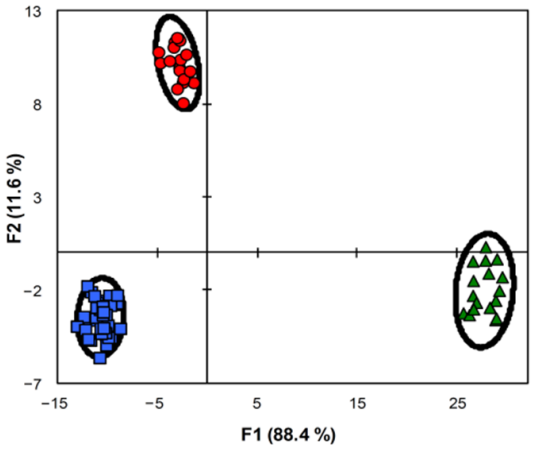

(f) 


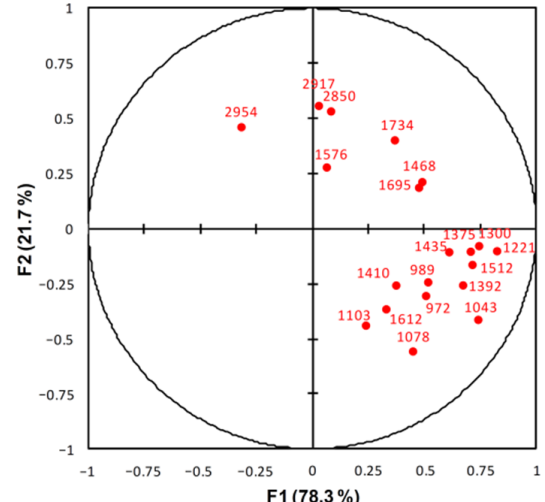

(a)

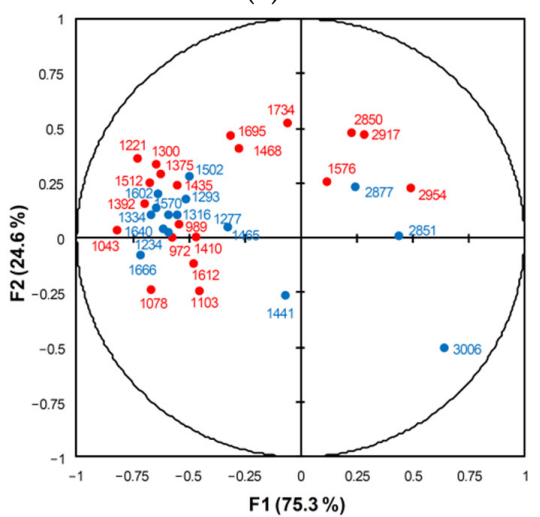

(d)

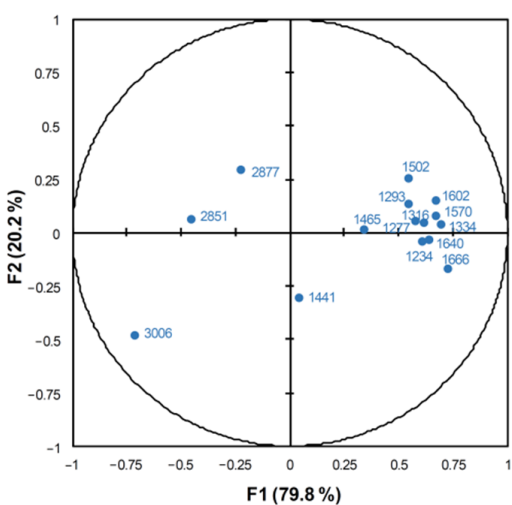

(b)

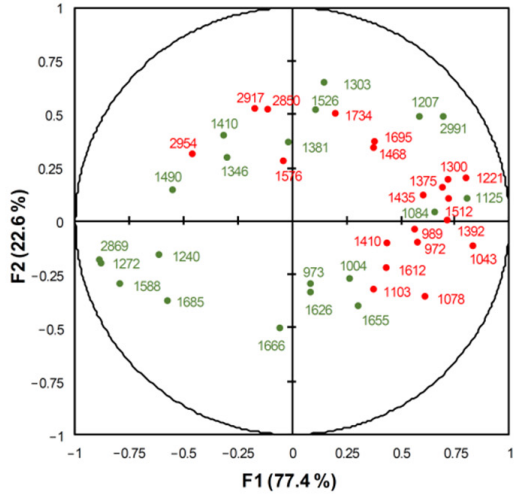

(e)

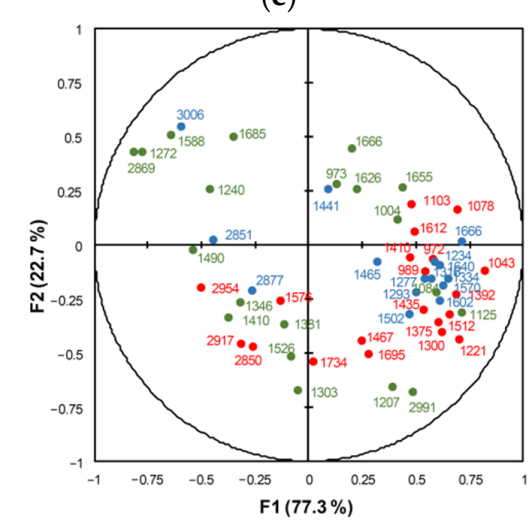

(g)

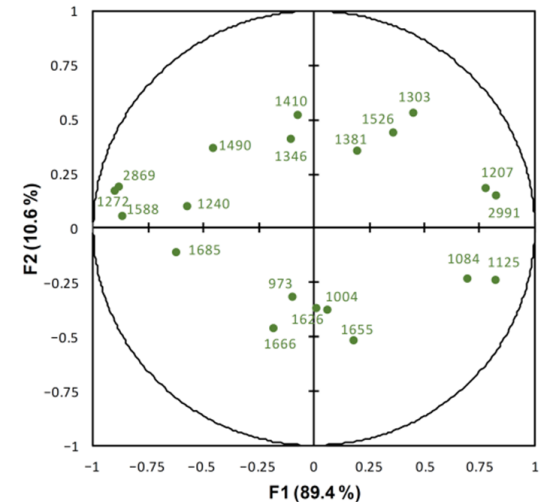

(c)

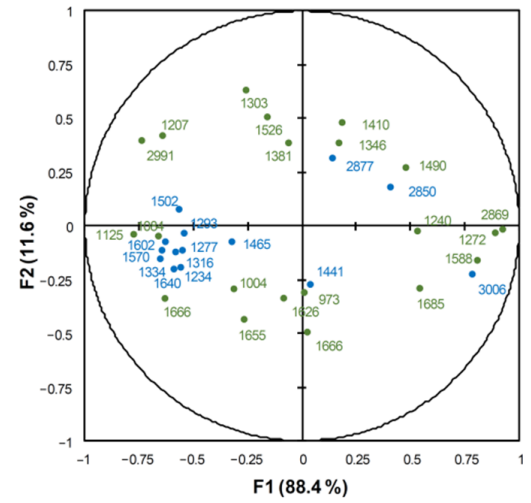

(f)

Figure 4. Variables / factor correlation plots for FTIR ((a), red), FT Raman ((b), blue), dispersion Raman (c, green), FTIR + FT Raman ((d), red and blue), FTIR + dispersion Raman ((e), red and green), FT Raman + dispersion Raman ((f), blue and green), and FTIR + FT Raman + dispersion Raman $((\mathrm{g})$, all colors) datasets.

The LDA discrimination of the three diagnostic groups mentioned above using individual sets of variables or their combination is represented in 3D plots as squared Mahalanobis distances (Figure 5), describing both the distance between groups and the distance of individual group members (samples) from the group center [51]. The values of these distances for individual datasets are summarized in Table S2. It is evident that all methods discriminated these three groups more or less effectively, however, using the combined pair datasets (Figure 5d-f) led to better results compared to the corresponding individual datasets (Figure $5 \mathrm{a}-\mathrm{c}$ ). The best discrimination was obtained using the triple combined dataset which significantly improved the individual vibrational spectroscopic methods (Figure 5g). In this case, three compact groups were located at a considerable distance from one another. To evaluate the separation of diagnostic groups, the distances between them were calculated based on the squared Mahalanobis distances from the LDA 
of all the datasets (Table 2). The distances obtained by LDA of the triple combined dataset $(\sim 4800-8130)$ were an order of magnitude longer than those obtained by the LDA of the individual spectroscopic datasets that increased in the raw FTIR ( 330-1050)—dispersion Raman ( 88-360)—FT Raman ( 64-330). A significant increase in the distances was also achieved for all pair of combined datasets ( 517-3243). Among the diagnostic groups, the longest distances were observed between normal colon tissues and one of the groups of colorectal polyps, adenomatous (FT Raman and all combined) or adenocarcinomatous (FTIR and dispersion Raman) polyps. For all but the triple combined spectroscopic datasets, the smallest distance was between the benign and malignant colon polyps. For the combined datasets, the differences between these distances were not as significant for the separation, since the diagnostic groups were compact and sufficiently distant from one another.

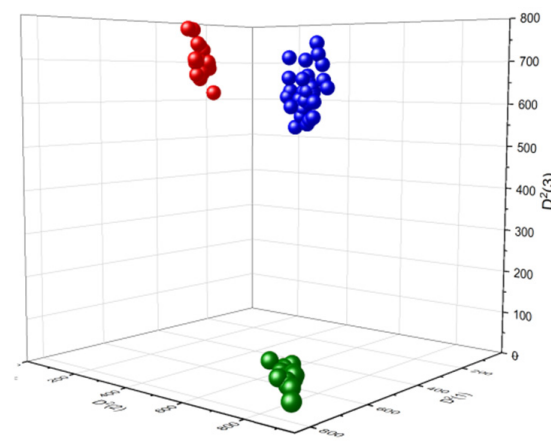

(a)

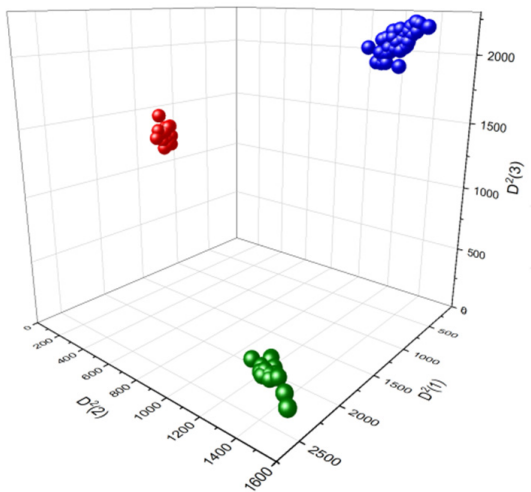

(d)

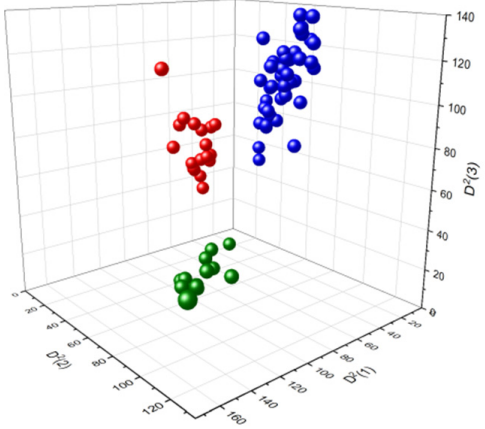

(b)

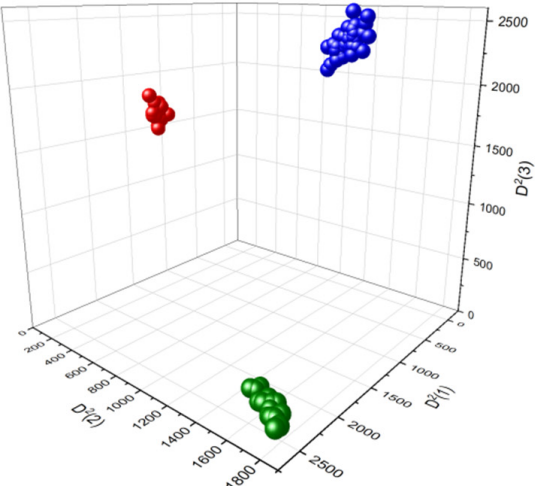

(e)

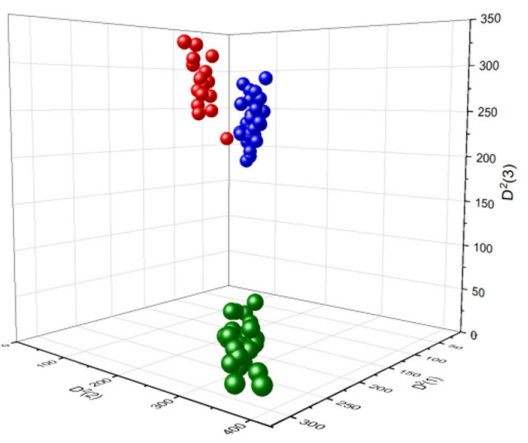

(c)

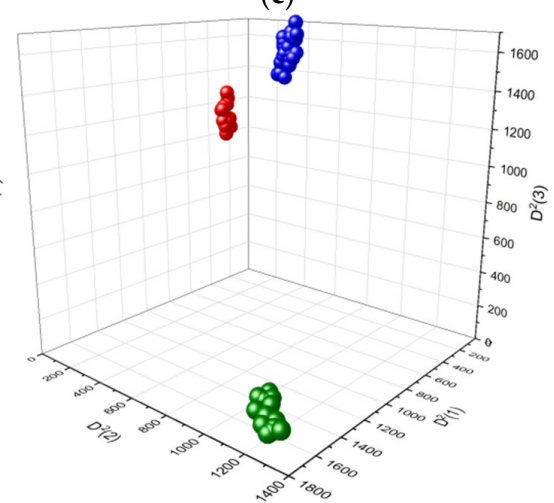

(f)

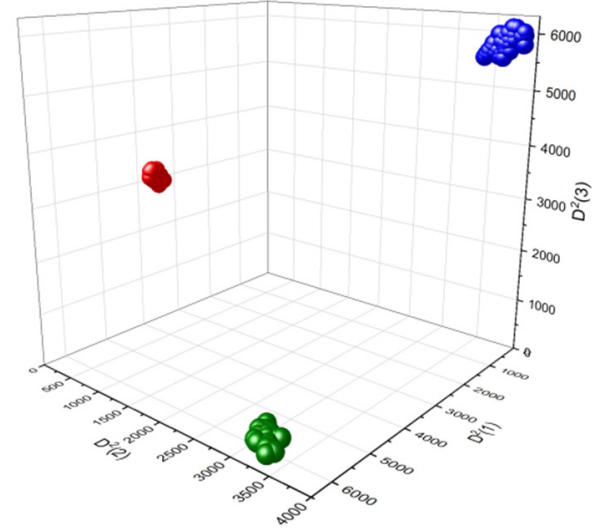

(g)

Figure 5. The squared Mahalanobis distances calculated for FTIR (a), FT Raman (b), dispersion Raman (c), FTIR + FT Raman (d), FTIR + dispersion Raman (e), FT Raman + dispersion Raman (f), and FTIR + FT Raman + dispersion Raman (g) datasets demonstrating discrimination of normal colon tissues (green triangles), adenomatous (blue squares), and adenocarcinomatous (red rings) colon polyps by LDA. 
Table 2. Distances between the diagnostic groups $d_{i j}$ determined by LDA using seven datasets: normal colon tissues " $\mathrm{n}$ ", adenomatous " $a$ ", and adenocarcinomatous "c" colon polyps.

\begin{tabular}{cccc}
\hline \multirow{2}{*}{ Dataset } & \multicolumn{3}{c}{ Distances between the Diagnostic Groups (Mean \pm SD) } \\
\cline { 2 - 4 } & $\mathbf{n} \leftrightarrow \mathbf{a}$ & $\mathbf{n} \leftrightarrow \mathbf{c}$ & $\mathbf{a} \leftrightarrow \mathbf{c}$ \\
\hline FTIR & $959.2 \pm 43.5$ & $1048.2 \pm 39.4$ & $329.0 \pm 25.8$ \\
\hline FT Raman & $329.0 \pm 17.4$ & $83.6 \pm 16.4$ & $63.8 \pm 16.4$ \\
\hline Dispersion Raman & $314.9 \pm 31.9$ & $360.5 \pm 33.5$ & $88.3 \pm 24.6$ \\
\hline FTIR + FT Raman & $2859.5 \pm 69.8$ & $1944.4 \pm 65.8$ & $1793.5 \pm 65.0$ \\
\hline FTIR + Dispersion Raman & $3243.1 \pm 79.0$ & $2548 \pm 70.2$ & $1648.0 \pm 68.6$ \\
\hline FT Raman + Disp. Raman & $2243.3 \pm 72.0$ & $1965.1 \pm 73.4$ & $516.9 \pm 61.5$ \\
\hline FTIR + FT Raman + Disp. Raman & $8127.4 \pm 146.6$ & $4798.5 \pm 118.3$ & $5718.0 \pm 102.8$ \\
\hline
\end{tabular}

\section{Discussion}

Significant spectral differences between normal colon tissues and adenomatous and adenocarcinomatous colon polyps described in the previous chapter were explained by the difference in the contributions of the main tissue constituents, including lipids, nucleic acids, proteins, and polysaccharides. The characteristic bands of these compounds demonstrated more or less sensitivity to the neoplastic transformation of the colon tissue.

Currently, many malignant neoplasms, including colorectal carcinoma, are accompanied by significant changes in lipid metabolism [52]. Consequently, some lipids may be potential biomarkers of the stage and risk of this disease. Indeed, the current investigation confirmed that, based on the average spectra of colorectal polyps, vibrational bands of lipids at $\sim 2918,2877-2891,2840-2852, \sim 1734,1465-1470$, and $\sim 1300 \mathrm{~cm}^{-1}$ could be assigned as spectral markers of a cancerous transformation. In addition, the phosphate vibration bands in the regions of 1080-1089 and 1234-1238 $\mathrm{cm}^{-1}$, which mainly arose from phospholipids and nucleic acids, as well as the bands of unsaturated fatty acids at 3008-3015, 2889, 1653-1659, and 1259-1271 $\mathrm{cm}^{-1}$, also contributed to the discrimination between normal colon tissues and colorectal polyps. However, this contribution was not as pronounced because of the overlapping protein and/or carbohydrate bands. The intense lipid bands found in the spectra of malignant polyps could be associated with an increase in the tissue content of these compounds compared with the normal colon tissue, as previously shown in some reports [53,54]. Partially, an increase in the total level of phosphatidylcholine was observed in the later stages of colorectal carcinoma [55].

LDA analysis of the current study has shown that vibrational bands of nucleic acid at about 2950-2960, 1574-1576, 1483-1484, 1310-1372, and $966 \mathrm{~cm}^{-1}$ may contribute to the identification of colon polyps. The increase in the DNA content, together with other biomarkers of high or abnormal DNA activity, have been successfully used to identify more aggressive colorectal adenomas with an increased potential for malignant transformation [56]. The DNA index, shape, and density of the nucleus have proven to be valuable indicators for distinguishing between normal colon mucosa, adenoma, and adenocarcinoma [57], and thus the DNA contribution to vibration spectra of the colon tissues and colon polyps, especially the bands associated with the vibrations of purine nucleotide bases $(A, G)$, could be significant for the early diagnosis of CRC.

In the current work, it was determined that the characteristic vibrational bands of proteins, in particular collagens, are very promising for distinguishing normal colon tissues from benign and malignant colorectal polyps. In general, it was determined that bands associated with vibrations of peptide groups and amino acid side chains, including those specific for collagens (Pro, Hyp), were more pronounced for colon polyps than for normal colon tissue. The differences in collagen marker bands point to the changes in the amount, structure, and conformation of these proteins. Changes in collagen density and alignment have been detected in high-grade dysplasia polyps and malignant specimens [58]. The 
diagnostic factor may not be the content of collagen in the cancer tissue, but the ratio between the individual structural forms (subtypes) of this protein that play specific roles in carcinogenesis. For example, collagen I inhibits the differentiation of human colorectal carcinoma cells and promotes their stem cell-like phenotype [59], and changes in the collagen I expression could be an early event in colorectal carcinoma informative for prognosis [60]. In contrast, the expression of collagen XVII correlates with the invasion and metastasis of colorectal cancer [61]. In addition, the collagen IV content was significantly correlated with the stage and histological grade of colorectal carcinoma [62].

The polysaccharides of the intercellular matrix, known as glycosaminoglycans (GAGs), also contribute to the vibrational spectra of colon tissues and colon polyps, especially in the regions of $1660-1400,1260-1210,1200-950$, and $860-810 \mathrm{~cm}^{-1}$, corresponding to stretching/bending vibrations of $\mathrm{CONH} / \mathrm{COO}^{-}, \mathrm{S}=\mathrm{O}, \mathrm{CO} / \mathrm{CC}$, and $\mathrm{HCS}$ bonds in these polysaccharides, respectively [63-66]. GAGs undergo significant structural alterations in cancer, including changes in their hydrodynamic size and sulfation patterns [67]. The amount of individual polysaccharides and more complex proteoglycans can also be changed. For example, the heparin sulfate and chondroitin sulfate levels were significantly increased in colon carcinomas, while the level of collagen-associated proteoglycan decorin decreased in some cases [68]. Typically, the content of chondroitin sulfates in cancerous tissue is significantly higher than that in normal tissue. In colon cancer, the level of chondroitin/dermatan C-4 sulfate increased in terms of normal adjacent and tumor tissues by approximately 1.5 times compared with the healthy control tissue, while the content of chondroitin C6 sulfate increased by 2.5 times in tumor tissue compared with normal adjacent tissue, and non-sulfated chondroitin was found only in the tumor tissue [69]. In addition to sulfated GAGs, hyaluronic acid is also a promising prognostic marker for colorectal carcinoma [70,71]. Despite the high variability of this polysaccharide in the cytosol attributed to the biological heterogeneity of colorectal cancer, high cytosolic levels have been associated with a poor prognosis.

Glycogen, an energy storage polymer of glucose, is also known as a metabolic marker of colorectal carcinoma. Carcinogenesis often leads to an unusual increase in glycogen storage because it affects the cellular catabolism involving glucose [72]. In the current work, despite overlapping by other vibration modes, the $\mathrm{CO}$ and $\mathrm{CC}$ stretching vibrations of this polysaccharide at $950-1150 \mathrm{~cm}^{-1}$ may contribute to a spectroscopic distinction between normal colon tissues, and adenomatous and adenocarcinomatous colon polyps. Glycogen levels were measured early in normal and cancerous human colorectal tissues [73]. The highest glycogen levels were found in adenocarcinoma, which were lower in the normal colon tissue and the lowest in the areas proximal to the tumor. The accumulation of glycogen varied with the type and stage of adenoma or adenocarcinoma. In adenocarcinomas, the level of glycogen depends on the phase of cell proliferation, since malignant tissues are able to supply themselves with glycogen and take it from the surrounding tissues as an energy source for the biosynthesis of DNA and proteins.

Summarizing what has been discussed above regarding the biopolymeric components of the colon tissues, it should be noted that the contribution of these macromolecular substances to the vibrational spectra of tissues is not always clear due to the strong overlap of the bands. Therefore, it is often difficult to determine which of these components is a chemical marker of pathological changes. Despite some uncertainty in the interpretation of the number of bands in the FTIR and Raman spectra, the application of multivariate statistical methods, namely the combination of PCA and LDA, in the evaluation of vibrational spectroscopic data, made it possible to successfully distinguish ex vivo benign and malignant colon polyps from one another and from normal colon tissue. Such a combination of vibrational spectroscopy and multivariate statistics can serve as an additional tool for the early diagnosis of colorectal carcinoma. 


\section{Conclusions}

Average FTIR, FT Raman $\left(\lambda_{\text {ex }} 1064 \mathrm{~nm}\right)$, and dispersion Raman $\left(\lambda_{\mathrm{ex}} 785 \mathrm{~nm}\right)$ spectra of normal colon tissue, and benign and malignant colon polyps obtained from surged or endoscopic patients demonstrated evident spectral differences in terms of the intensities and positions of characteristic bands assigned to vibrations of main tissue constituents, i.e., proteins, lipids, polysaccharides, etc. A suitable statistical model allowed us to discriminate normal, abnormal, and cancerous colon tissue samples based on a multivariate analysis of the vibrational spectroscopic data. LDA classification was especially successful in the case of combined set of 55 variables from FTIR, FT Raman, and dispersion Raman spectra. This model can be proposed for ex vivo colorectal cancer diagnostics in combination with colonoscopic extraction of colon polyps for further testing. The pilot study presented here is a precursor for the further evaluation of diagnostic potential for simultaneous in vivo application of endoscopic Raman probes.

Supplementary Materials: The following are available online at https:/ /www.mdpi.com/article/10 .3390/diagnostics11112048/s1, Figure S1a-c: FTIR (a), FT Raman (b) and dispersion Raman (c) spectra of the model standard compounds, Figure S2. Average FTIR ATR spectra and 2nd derivations of these spectra of the normal colon tissues, adenomatous and adenocarcinomatous colon polyps, Figure S3. The component score plot PC1 versus PC2 for FTIR spectra of the normal colon tissues, adenomatous and adenocarcinomatous (red rings) colorectal polyps. Table S1: Wavenumbers (in $\mathrm{cm}^{-1}$ ) and assignments of vibration bands for the average spectra of normal colon tissue " $n$ ", adenomatous "a" and adenocarcinomatous " $c$ " colon polyps, Table S2: Squared Mahalanobis distances for normal colon tissues " $\mathrm{n}$ ", adenomatous " $\mathrm{a}$ " and adenocarcinomatous " $\mathrm{c}$ " colon polyps determined by LDA using four spectral datasets.

Author Contributions: Conceptualization, A.S. and L.P.; methodology, A.S. and J.P.; software, A.S.; validation, A.S., M.M. and A.V.; formal analysis, A.S., A.V. and J.P.; investigation, A.S. and M.M.; resources, J.P. and M.M.; data curation, A.S.; writing—original draft preparation, A.S.; writingreview and editing, A.S.; visualization, A.S. and A.V.; supervision, A.S.; project administration, L.P. and M.M.; funding acquisition, L.P. All authors have read and agreed to the published version of the manuscript.

Funding: This research was funded by the Ministry of Health of the Czech Republic; grant number NU20-09-00229.

Institutional Review Board Statement: The study was conducted according to the guidelines of the Declaration of Helsinki, and approved by Ethics Committee of the 1st Faculty of Medicine and the General University Hospital in Prague (Project NU20-09-00229, 18 June 2020).

Informed Consent Statement: Written informed consent has been obtained from the patients to publish this paper.

Data Availability Statement: Not applicable.

Conflicts of Interest: The authors declare no conflict of interest. The funders had no role in the design of the study; in the collection, analyses, or interpretation of data; in the writing of the manuscript, or in the decision to publish the results.

\section{Appendix A}

The squared Mahalanobis distances $D^{2}(1), D^{2}(2)$ and $D^{2}(3)$ (mean $\pm \mathrm{SD}$ ) represented in Table S2 were calculated for each diagnostic group, i.e., normal colon tissues " $\mathrm{n}$ ", adenomatous colon polyps " $a$ " and adenocarcinomatous colon polyps " $c$ ", from the corresponding values obtained for each measurement site by the LDA classification using the XLSTAT software (Addinsoft, France). The distances between the three diagnostic groups $d_{i j}$ ( $i$ and $j$ are the diagnostic groups) represented in Table 2 were calculated from the squared Mahalanobis distances of the corresponding groups according to the equation:

$$
d_{i j}=\sqrt{\left(D^{2}(1)_{i}-D^{2}(1)_{j}\right)^{2}+\left(D^{2}(2)_{i}-D^{2}(2)_{j}\right)^{2}+\left(D^{2}(3)_{i}-D^{2}(3)_{j}\right)^{2}}
$$




\section{References}

1. Ciocalteu, A.; Gheonea, D.I.; Saftoiu, A.; Streba, L.; Dragoescu, N.A.; Tenea-Cojan, T.S. Current strategies for malignant pedunculated colorectal polyps. World J. Gastrointest. Oncol. 2018, 10, 465. [CrossRef] [PubMed]

2. Johnstone, M.S.; Lynch, G.; Park, J.; McSorley, S.; Edwards, J. Novel methods of risk stratifying patients for metachronous, pre-malignant colorectal polyps: A systematic review. Crit. Rev. Oncol. Hematol. 2021, 164, 103421. [CrossRef] [PubMed]

3. Nguyen, L.H.; Goel, A.; Chung, D.C. Pathways of colorectal carcinogenesis. Gastroenterology 2020, 158, 291-302. [CrossRef] [PubMed]

4. Aceto, G.M.; Catalano, T.; Curia, M.C. Molecular aspects of colorectal adenomas: The interplay among microenvironment, oxidative stress, and predisposition. Bio. Med. Res. Int. 2020, 2020, 1726309. [CrossRef] [PubMed]

5. Shaukat, A.; Shyne, M.; Mandel, J.S.; Snover, D.; Church, T.R. Colonoscopy with polypectomy reduces long-term incidence of colorectal cancer in both men and women: Extended results from the minnesota colon cancer control study. Gastroenterology 2021, 160, 1397-1399. [CrossRef]

6. Romiti, A.; Roberto, M.; Marchetti, P.; Di Cerbo, A.; Falcone, R.; Campisi, G.; Ferri, M.; Balducci, G.; Ramacciato, G.; Ruco, L.; et al. Study of histopathologic parameters to define the prognosis of stage II colon cancer. Int. J. Colorectal Dis. 2019, 34, 905-913. [CrossRef]

7. Kallenbach-Thieltges, A.; Großerüschkamp, F.; Mosig, A.; Diem, M.; Tannapfel, A.; Gerwert, K. Immunohistochemistry, histopathology and infrared spectral histopathology of colon cancer tissue sections. J. Biophotonics 2013, 6, 88-100. [CrossRef]

8. Marzouk, O.; Schofield, J. Review of histopathological and molecular prognostic features in colorectal cancer. Cancers 2011, 3, 2767-2810. [CrossRef] [PubMed]

9. Noothalapati, H.; Iwasaki, K.; Yamamoto, T. Non-invasive diagnosis of colorectal cancer by Raman spectroscopy: Recent developments in liquid biopsy and endoscopy approaches. Spectrochim. Acta A Mol. Biomol. Spectrosc. 2021, $258,119818$. [CrossRef]

10. Kallaway, C.; Almond, L.M.; Barr, H.; Wood, J.; Hutchings, J.; Kendall, C.; Stone, N. Advances in the clinical application of Raman spectroscopy for cancer diagnostics. Photodiagn. Photodyn. Ther. 2013, 10, 207-219. [CrossRef]

11. Dong, L.; Sun, X.; Chao, Z.; Zhang, S.; Zheng, J.; Gurung, R.; Du, J.; Shi, J.; Xu, Y.; Zhang, Y. Evaluation of FTIR spectroscopy as diagnostic tool for colorectal cancer using spectral analysis. Spectrochim. Acta Part A Mol. Biomol. Spectrosc. 2014, 122, 288-294. [CrossRef]

12. Kim, Y.I.; Jeong, S.; Jung, K.O.; Song, M.G.; Lee, C.H.; Chung, S.J.; Park, J.Y.; Cha, M.G.; Lee, S.G.; Jun, B.H.; et al. Simultaneous detection of EGFR and VEGF in colorectal cancer using fluorescence-Raman endoscopy. Sci. Rep. 2017, 7, 1035. [CrossRef] [PubMed]

13. Petersen, D.; Naveed, P.; Ragheb, A.; Niedieker, D.; El-Mashtoly, S.F.; Brechmann, T.; Kötting, C.; Schmiegel, W.H.; Freier, E.; Pox, C.; et al. Raman fiber-optical method for colon cancer detection: Cross-validation and outlier identification approach. Spectrochim. Acta Part A Mol. Biomol. Spectrosc. 2017, 181, 270-275. [CrossRef] [PubMed]

14. Bergholt, M.S.; Lin, K.; Wang, J.; Zheng, W.; Xu, H.; Huang, Q.; Ren, J.-L.; Ho, K.Y.; The, M.; Srivastava, S.; et al. Simultaneous fingerprint and high-wavenumber fiber-optic Raman spectroscopy enhances real-time in vivo diagnosis of adenomatous polyps during colonoscopy. J. Biophotonics 2016, 9, 333-342. [CrossRef] [PubMed]

15. Jenkins, C.A.; Jenkins, R.A.; Pryse, M.M.; Welsby, K.A.; Jitsumura, M.; Thornton, C.A.; Dunstan, P.R.; Harris, D.A. A highthroughput serum Raman spectroscopy platform and methodology for colorectal cancer diagnostics. Analyst 2018, 143, 6014-6024. [CrossRef]

16. Synytsya, A.; Judexova, M.; Hoskovec, D.; Miskovicova, M.; Petruzelka, L. Raman spectroscopy at different excitation wavelengths (1064, 785 and $532 \mathrm{~nm}$ ) as a tool for diagnosis of colon cancer. J. Raman Spectrosc. 2014, 45, 903-911. [CrossRef]

17. Li, Q.B.; Xu, Z.; Zhang, N.W.; Zhang, L.; Wang, F.; Yang, L.M.; Wang, J.S.; Zhou, S.; Zhang, Y.F.; Zhou, X.S.; et al. In vivo and in situ detection of colorectal cancer using Fourier transform infrared spectroscopy. World J. Gastroenterol. 2005, 11, 327. [CrossRef]

18. Li, S.; Chen, G.; Zhang, Y.; Guo, Z.; Liu, Z.; Xu, J.; Li, X.; Lin, L. Identification and characterization of colorectal cancer using Raman spectroscopy and feature selection techniques. Opt. Express 2014, 22, 25895-25908. [CrossRef]

19. Zheng, F.; Chen, K.; Qin, Y. Sensitivity map of laser tweezers Raman spectroscopy for single-cell analysis of colorectal cancer. J. Biomed. Opt. 2007, 12, 034002. [CrossRef]

20. Chen, K.; Qin, Y.; Zheng, F.; Sun, M.; Shi, D. Diagnosis of colorectal cancer using Raman spectroscopy of laser-trapped single living epithelial cells. Opt. Lett. 2006, 31, 2015-2017. [CrossRef]

21. Yan, X.L.; Dong, R.X.; Zhang, L.; Zhang, X.J.; Zhang, Z.W. Raman spectra of single cell from gastrointestinal cancer patients. World J. Gastroenterol. 2005, 11, 3290. [CrossRef] [PubMed]

22. Petersen, D.; Mavarani, L.; Niedieker, D.; Freier, E.; Tannapfel, A.; Kötting, C.; Gerwert, K.; El-Mashtoly, S.F. Virtual staining of colon cancer tissue by label-free Raman micro-spectroscopy. Analyst 2017, 142, 1207-1215. [CrossRef]

23. Lloyd, G.R.; Wood, J.; Kendall, C.; Cook, T.; Shepherd, N.; Stone, N. Histological imaging of a human colon polyp sample using Raman spectroscopy and self organising maps. Vib. Spectrosc. 2012, 60, 43-49. [CrossRef]

24. Liu, W.; Wang, H.; Du, J.; Jing, C. Raman microspectroscopy of nucleus and cytoplasm for human colon cancer diagnosis. Biosens. Bioelectron. 2017, 97, 70-74. [CrossRef] [PubMed]

25. Li, X.; Yang, T.; Li, S.; Zhang, S.; Jin, L. Discrimination of rectal cancer through human serum using surface-enhanced Raman spectroscopy. Appl. Phys. B 2015, 119, 393-398. [CrossRef] 
26. Miskovicova, M.; Fryba, V.; Petruzelka, L.; Setnicka, V.; Synytsya, A.; Tatarkovic, M.; Ulrych, J.; Vocka, M. Novel spectroscopic biomarkers are applicable in non-invasive early detection and staging classification of colorectal cancer. Neoplasma 2020, 67, 1349-1358. [CrossRef]

27. Tatarkovič, M.; Miškovičová, M.; Št'ovíčková, L.; Synytsya, A.; Petruželka, L.; Setnička, V. The potential of chiroptical and vibrational spectroscopy of blood plasma for the discrimination between colon cancer patients and the control group. Analyst 2015, 140, 2287-2293. [CrossRef] [PubMed]

28. Wang, J.; Lin, D.; Lin, J.; Yu, Y.; Huang, Z.; Chen, Y.; Lin, J.; Feng, S.; Li, B.; Liu, N.; et al. Label-free detection of serum proteins using surface-enhanced Raman spectroscopy for colorectal cancer screening. J. Biomed. Opt. 2014, 19, 087003. [CrossRef] [PubMed]

29. Synytsya, A.; Judexová, M.; Hrubý, T.; Tatarkovič, M.; Miškovičová, M.; Petruželka, L.; Setnička, V. Analysis of human blood plasma and hen egg white by chiroptical spectroscopic methods. Anal. Bioanal. Chem. 2013, 405, 5441-5453. [CrossRef]

30. Liu, W.; Sun, Z.; Chen, J.; Jing, C. Raman spectroscopy in colorectal cancer diagnostics: Comparison of PCA-LDA and PLS-DA models. J. Spectrosc. 2016, 2016, 1603609. [CrossRef]

31. Choi, J.S.; Kim, J.; Hong, Y.J.; Bae, W.Y.; Choi, E.H.; Jeong, J.W.; Park, H.K. Evaluation of non-thermal plasma-induced anticancer effects on human colon cancer cells. Biomed. Opt. Express 2017, 8, 2649-2659. [CrossRef]

32. Kaznowska, E.; Depciuch, J.; Szmuc, K.; Cebulski, J. Use of FTIR spectroscopy and PCA-LDC analysis to identify cancerous lesions within the human colon. J. Pharm. Biomed. Anal. 2017, 134, 259-268. [CrossRef]

33. Li, X.; Yang, T.; Li, S.; Wang, D.; Song, Y.; Zhang, S. Raman spectroscopy combined with principal component analysis and k nearest neighbour analysis for non-invasive detection of colon cancer. Laser Phys. 2016, 26, 035702. [CrossRef]

34. Khanmohammadi, M.; Garmarudi, A.B.; Samani, S.; Ghasemi, K.; Ashuri, A. Application of linear discriminant analysis and attenuated total reflectance Fourier transform infrared microspectroscopy for diagnosis of colon cancer. Pathol. Oncol. Res. 2011, 17, 435-441. [CrossRef]

35. Molckovsky, A.; Song, L.M.W.K.; Shim, M.G.; Marcon, N.E.; Wilson, B.C. Diagnostic potential of near-infrared Raman spectroscopy in the colon: Differentiating adenomatous from hyperplastic polyps. Gastrointest. Endosc. 2003, 57, 396-402. [CrossRef]

36. Manavbasi, Y.; Süleymanoglu, E. Nucleic acid-phospholipid recognition: Fourier transform infrared spectrometric characterization of ternary phospho-lipid-inorganic cation-DNA complex and its relevance to chemicopharmaceutical design of nanometric liposome based gene delivery formulations. Arch. Pharm. Res. 2007, 30, 1027-1040. [CrossRef] [PubMed]

37. Movasaghi, Z.; Rehman, S.; Rehman, D.I. Fourier transform infrared (FTIR) spectroscopy of biological tissues. Appl. Spectrosc. Rev. 2008, 43, 134-179. [CrossRef]

38. Yao, H.; Shi, X.; Zhang, Y. The use of FTIR-ATR spectrometry for evaluation of surgical resection margin in colorectal cancer: A pilot study of 56 samples. J. Spectrosc. 2014, 2014, 213890. [CrossRef]

39. Ramesh, J.; Salman, A.; Mordechai, S.; Argov, S.; Goldstein, J.; Sinelnikov, I.; Walfish, S.; Guterman, H. FTIR microscopic studies on normal, polyp, and malignant human colonic tissues. Subsurf. Sens. Technol. Appl. 2001, 2, 99-117. [CrossRef]

40. Barth, A. The infrared absorption of amino acid side chains. Prog. Biophys. Mol. Biol. 2000, 74, 141-173. [CrossRef]

41. Kondepati, V.R.; Heise, H.M.; Oszinda, T.; Mueller, R.; Keese, M.; Backhaus, J. Detection of structural disorders in colorectal cancer DNA with Fourier-transform infrared spectroscopy. Vib. Spectrosc. 2008, 46, 150-157. [CrossRef]

42. Olsztyńska-Janus, S.; Komorowska, M. Conformational changes of L-phenylalanine induced by near infrared radiation. ATR-FTIR studies. Struct. Chem. 2012, 23, 1399-1407. [CrossRef]

43. Olsztynska, S.; Komorowska, M.; Vrielynck, L.; Dupuy, N. Vibrational spectroscopic study of L-phenylalanine: Effect of pH. Appl. Spectrosc. 2001, 55, 901-907. [CrossRef]

44. Hernández, B.; Pflüger, F.; Adenier, A.; Kruglik, S.G.; Ghomi, M. Vibrational analysis of amino acids and short peptides in hydrated media. VIII. Amino acids with aromatic side chains: L-phenylalanine, L-tyrosine, and L-tryptophan. J. Phys. Chem. B 2010, 114, 15319-15330. [CrossRef]

45. Czamara, K.; Majzner, K.; Pacia, M.Z.; Kochan, K.; Kaczor, A.; Baranska, M. Raman spectroscopy of lipids: A review. J. Raman Spectrosc. 2015, 46, 4-20. [CrossRef]

46. Beattie, J.R.; Bell, S.E.; Moss, B.W. A critical evaluation of Raman spectroscopy for the analysis of lipids: Fatty acid methyl esters. Lipids 2004, 39, 407-419. [CrossRef]

47. Krafft, C.; Ramoji, A.A.; Bielecki, C.; Vogler, N.; Meyer, T.; Akimov, D.; Rösch, P.; Schmitt, M.; Dietzek, B.; Petersen, I.; et al. A comparative Raman and CARS imaging study of colon tissue. J. Biophotonics 2009, 2, 303-312. [CrossRef] [PubMed]

48. Wood, B.R.; Caspers, P.; Puppels, G.J.; Pandiancherri, S.; McNaughton, D. Resonance Raman spectroscopy of red blood cells using near-infrared laser excitation. Anal. Bioanal. Chem. 2007, 387, 1691-1703. [CrossRef]

49. Hu, S.; Smith, K.M.; Spiro, T.G. Assignment of protoheme resonance Raman spectrum by heme labeling in myoglobin. J. Am. Chem. Soc. 1996, 118, 12638-12646. [CrossRef]

50. Brazhe, N.A.; Treiman, M.; Brazhe, A.R.; Find, N.L.; Maksimov, G.V.; Sosnovtseva, O.V. Mapping of redox state of mitochondrial cytochromes in live cardiomyocytes using Raman microspectroscopy. PLoS ONE 2012, 7, e41990. [CrossRef]

51. De Maesschalck, R.; Jouan-Rimbaud, D.; Massart, D.L. The Mahalanobis distance. Chemom. Intell. Lab. Syst. 2000, 50, 1-18. [CrossRef]

52. Pakiet, A.; Kobiela, J.; Stepnowski, P.; Sledzinski, T.; Mika, A. Changes in lipids composition and metabolism in colorectal cancer: A review. Lipids Health Dis. 2019, 18, 29. [CrossRef] [PubMed] 
53. Scalfi-Happ, C.; Udart, M.; Hauser, C.; Rück, A. Investigation of lipid bodies in a colon carcinoma cell line by confocal Raman microscopy. Med. Laser Appl. 2011, 26, 152-157. [CrossRef]

54. Accioly, M.T.; Pacheco, P.; Maya-Monteiro, C.M.; Carrossini, N.; Robbs, B.K.; Oliveira, S.S.; Kaufmann, K.; Morgado-Diaz, J.A.; Bozza, P.T.; Viola, J.P. Lipid bodies are reservoirs of cyclooxygenase-2 and sites of prostaglandin-E2 synthesis in colon cancer cells. Cancer Res. 2008, 68, 1732-1740. [CrossRef]

55. Kurabe, N.; Hayasaka, T.; Ogawa, M.; Masaki, N.; Ide, Y.; Waki, M.; Nakamura, T.; Kurachi, K.; Kahyo, T.; Shinmura, K.; et al. Accumulated phosphatidylcholine (16:0/16:1) in human colorectal cancer; possible involvement of LPCAT 4. Cancer Sci. 2013, 104, 1295-1302. [CrossRef]

56. Lavezzi, A.M.; Ottaviani, G.; De Ruberto, F.; Fichera, G.; Matturri, L. Prognostic significance of different biomarkers (DNA content, PCNA, karyotype) in colorectal adenomas. Anticancer Res. 2002, 22, 2077-2081.

57. Jin, W.; Gao, M.Q.; Lin, Z.W.; Yang, D.X. Quantitative study of multiple biomarkers of colorectal tumor with diagnostic discrimination model. World J. Gastroenterol. 2004, 10, 439. [CrossRef]

58. Birk, J.W.; Tadros, M.; Moezardalan, K.; Nadyarnykh, O.; Forouhar, F.; Anderson, J.; Campagnola, P. Second harmonic generation imaging distinguishes both high-grade dysplasia and cancer from normal colonic mucosa. Dig. Dis. Sci. 2014, 59, 1529-1534. [CrossRef]

59. Kirkland, S.C. Type I collagen inhibits differentiation and promotes a stem cell-like phenotype in human colorectal carcinoma cells. Br. J. Cancer 2009, 101, 320-326. [CrossRef]

60. Zou, X.; Feng, B.; Dong, T.; Yan, G.; Tan, B.; Shen, H.; Huang, A.; Zhang, X.; Zhang, M.; Yang, P.; et al. Up-regulation of type I collagen during tumorigenesis of colorectal cancer revealed by quantitative proteomic analysis. J. Proteom. 2013, 94, $473-485$. [CrossRef]

61. Moilanen, J.M.; Kokkonen, N.; Löffek, S.; Väyrynen, J.P.; Syväniemi, E.; Hurskainen, T.; Mäkinen, M.; Klintrup, K.; Mäkelä, J.; Sormunen, R.; et al. Collagen XVII expression correlates with the invasion and metastasis of colorectal cancer. Hum. Pathol. 2015, 46, 434-442. [CrossRef] [PubMed]

62. Fenyvesi, A. The prognostic significance of type IV collagen expression in colorectal carcinomas. Arch. Oncol. 2003, 11, 65-70. [CrossRef]

63. Mohamed, H.T.; Untereiner, V.; Sockalingum, G.D.; Brézillon, S. Implementation of infrared and Raman modalities for glycosaminoglycan characterization in complex systems. Glycoconj. J. 2017, 34, 309-323. [CrossRef] [PubMed]

64. Brézillon, S.; Untereiner, V.; Lovergne, L.; Tadeo, I.; Noguera, R.; Maquart, F.X.; Wegrowski, Y.; Sockalingum, G.D. Glycosaminoglycan profiling in different cell types using infrared spectroscopy and imaging. Anal. Bioanal. Chem. 2014, 406, 5795-5803. [CrossRef]

65. Mainreck, N.; Brézillon, S.; Sockalingum, G.D.; Maquart, F.-X.; Manfait, M.; Wegrowski, Y. Characterization of glycosaminoglycans by tandem vibrational microspectroscopy and multivariate data analysis. Methods Mol. Biol. 2012, 836, 117-130.

66. Mainreck, N.; Brézillon, S.; Sockalingum, G.D.; Maquart, F.X.; Manfait, M.; Wegrowski, Y. Rapid characterization of glycosaminoglycans using a combined approach by infrared and Raman microspectroscopies. J. Pharm. Sci. 2011, 100, 441-450. [CrossRef]

67. Kalathas, D.; Theocharis, D.A.; Bounias, D.; Kyriakopoulou, D.; Papageorgakopoulou, N.; Stavropoulos, M.S.; Vynios, D.H. Chondroitin synthases I, II, III and chondroitin sulfate glucuronyltransferase expression in colorectal cancer. Mol. Med. Rep. 2011, 4, 363-368. [PubMed]

68. Brauchle, E.; Kasper, J.; Daum, R.; Schierbaum, N.; Falch, C.; Kirschniak, A.; Schäffer, T.E.; Schenke-Layland, K. Biomechanical and biomolecular characterization of extracellular matrix structures in human colon carcinomas. Matrix Biol. 2018, 68, 180-193. [CrossRef]

69. Kalathas, D.; Theocharis, D.A.; Bounias, D.; Kyriakopoulou, D.; Papageorgakopoulou, N.; Stavropoulos, M.S.; Vynios, D.H. Alterations of glycosaminoglycan disaccharide content and composition in colorectal cancer: Structural and expressional studies. Oncol. Rep. 2009, 22, 369-375.

70. Laneza, A.; Vizoso, F.; Rodriguez, J.C.; Raigoso, P.; Garcia-Muniz, J.L.; Allende, M.T.; Garcia-Moran, M. Hyaluronic acid as prognostic marker in resectable colorectal cancer. Br. J. Surg. 2000, 87, 1690-1696. [CrossRef]

71. Wu, R.L.; Huang, L.; Zhao, H.C.; Geng, X.P. Hyaluronic acid in digestive cancers. J. Cancer Res. Clin. Oncol. 2017, 143, 1-16. [CrossRef]

72. Annibaldi, A.; Widmann, C. Glucose metabolism in cancer cells. Curr. Opin. Clin. Nutr. Metab. Care 2010, 13, 466-470. [CrossRef] [PubMed]

73. Sakr, S.A.; Abdel-Wahed, M.M.; Abdou, A.G.; El-Adely, E.K. Histochemical alterations in colorectal carcinoma and adenoma in Egyptian patients. J. Coast. Life Med. 2016, 4, 14-20. [CrossRef] 